Article

\title{
Efficient Power Scheduling in Smart Homes Using Hybrid Grey Wolf Differential Evolution Optimization Technique with Real Time and Critical Peak Pricing Schemes
}

\author{
Muqaddas $\mathrm{Naz}^{1}$, Zafar Iqbal ${ }^{2}$ (i), Nadeem Javaid ${ }^{1, *(1)}$, Zahoor Ali Khan ${ }^{3}$ (i), Wadood Abdul ${ }^{4}$ (i), \\ Ahmad Almogren ${ }^{4}$ and Atif Alamri ${ }^{4}$ \\ 1 COMSATS Institute of Information Technology, Islamabad 44000, Pakistan; muqaddasawan532@gmail.com \\ PMAS, Arid Agriculture University, Rawalpindi 46000, Pakistan; iqbal.zafar9@gmail.com \\ CIS, Higher Colleges of Technology, Fujairah 4114, UAE; zkhan1@hct.ac.ae \\ 4 Research Chair of Pervasive and Mobile Computing, College of Computer and Information Sciences, \\ King Saud University, Riyadh 11633, Saudi Arabia; aabdulwaheed@ksu.edu.sa (W.A.); \\ ahalmogren@ksu.edu.sa (Ah.A.); atif@ksu.edu.sa (At.A.) \\ * Correspondence: nadeemjavaidqau@gmail.com; Tel.: +92-300-579-2728
}

Received: 17 December 2017; Accepted: 2 February 2018; Published: 7 February 2018

\begin{abstract}
With the emergence of automated environments, energy demand by consumers is increasing rapidly. More than $80 \%$ of total electricity is being consumed in the residential sector. This brings a challenging task of maintaining the balance between demand and generation of electric power. In order to meet such challenges, a traditional grid is renovated by integrating two-way communication between the consumer and generation unit. To reduce electricity cost and peak load demand, demand side management (DSM) is modeled as an optimization problem, and the solution is obtained by applying meta-heuristic techniques with different pricing schemes. In this paper, an optimization technique, the hybrid gray wolf differential evolution (HGWDE), is proposed by merging enhanced differential evolution (EDE) and gray wolf optimization (GWO) scheme using real-time pricing (RTP) and critical peak pricing (CPP). Load shifting is performed from on-peak hours to off-peak hours depending on the electricity cost defined by the utility. However, there is a trade-off between user comfort and cost. To validate the performance of the proposed algorithm, simulations have been carried out in MATLAB. Results illustrate that using RTP, the peak to average ratio (PAR) is reduced to $53.02 \%, 29.02 \%$ and $26.55 \%$, while the electricity bill is reduced to $12.81 \%$, $12.012 \%$ and $12.95 \%$, respectively, for the 15-, 30- and 60-min operational time interval (OTI). On the other hand, the PAR and electricity bill are reduced to $47.27 \%, 22.91 \%, 22 \%$ and $13.04 \%, 12 \%, 11.11 \%$ using the CPP tariff.
\end{abstract}

Keywords: home energy management; demand side; supply side; enhanced differential evolution; peak to average ratio; operational time interval

\section{Introduction}

Enhancement of the smart grid is increasing everyday in order to make a robust and reliable system. The world is now moving towards automation, hence increasing the electricity consumption due to excessive use of automatic equipment. Reduction in fossils fuels and high demand of electricity lead to a dependency on renewable energy sources (RES) [1]. Electricity production from RES is not a part of this debate. However, usage of electricity can be controlled through scheduling and coordination of appliances. According to the authors in [2], 38\% augmentation in consumption by 
the power sector is expected by the year 2020. For the residential and commercial sector, there is an expectation of a $16 \%$ upturn.

Considering the growth in electricity consumption, there is a need to reorganize the pattern of energy consumption and production on the demand and supply side [3]. For this purpose, the entire focus is to replace the traditional grid with a smart grid with the integration of the latest telecommunication technologies. Advanced metering infrastructure (AMI) provides two-way communication between the utility and consumer [4]. In a smart grid, the utility manages the electricity consumption and demand of the user by a specific set of rules. These rules are called demand response (DR) [5]. Multiple incentives are declared by the electric utility to encourage the consumer use electricity resources efficiently as explained in [6]. Pricing signals that are widely used are RTP, time of use (TOU), CPP, flat rate pricing (FRP), day-ahead pricing (DHP) and inclined block rate (IBR). The energy management controller (EMC) within a smart home receives the price signal from the utility. The schedule is generated by EMC using two inputs: price signal and load demand of the user. Appliances are synchronized with these schedules through WiFi, infrared or ZigBee [7].

Generally, the main focus lies in load shifting from on-peak hours to off-peak hours by applying different strategies such as load clipping and valley filling. Load shifting helps to achieve cost minimization by shifting the operation of appliances to low-price hours [8]. Although load shifting reduces the electricity bill, user discomfort increases due to the trade-off. In order to achieve these objectives, global optimization algorithms are mostly used due to their low complexity and fast convergence towards optimal points. Based on the aforementioned issues, we propose HGWDE to obtain cost minimization and load shifting.

As the demand of electricity in the residential sector is increasing rapidly, there is a need to adopt optimization strategies for efficient utilization of electric resources. This fact attracts researchers from around the globe to the issues of the sustainability of the electric grid. DR is very beneficial to encourage consumers by introducing incentive-based programs. In this paper, we designed a model using three different categories of appliances; shiftable, non-shiftable and controllable. Out of 17 appliances, each appliance has been assigned a category on the basis of their behavior and power ratings. LOT (length of operational time) is different for each appliance. Four parameters are taken into consideration, such as energy consumption, cost and PAR reduction and waiting time. RTP and $\mathrm{CPP}$ schemes are used as the pricing signal. Simulations have been performed in MATLAB to evaluate the behavior of our proposed scheme.

Rest of the paper is organized as follow: Related work is given in Section 2. Section 3 presents the system model. The proposed scheme is discussed in Section 4 . Section 5 describes the results and simulations, the conclusions are presented in Section 6, finally lists of acronyms and nomenclature are given in Tables 1 and 2.

Table 1. List of acronyms.

\begin{tabular}{cc}
\hline DSM & Demand side management \\
GWO & Gray wolf optimization \\
EDE & Enhanced differential evaluation \\
HGWDE & Hybrid gray wolf differential evaluation \\
BFA & Bacterial foraging optimization \\
PSO & Particle swarm optimization \\
BPSO & Binary particle swarm optimization \\
TLBO & Teaching- and learning-based optimization \\
IDSS & Intelligent decision support system \\
MOO & Multi-objective optimization \\
AMI & Advanced metering infrastructure \\
EMC & Energy management controller \\
LOT & Length of operational time \\
HEM & Home energy management \\
\hline
\end{tabular}


Table 1. Cont.

\begin{tabular}{cc}
\hline PAR & Peak to average ratio \\
RTP & Real-time pricing \\
CPP & Critical peak pricing \\
OTI & Operational time interval \\
RES & Renewable energy sources \\
DR & Demand response \\
WDO & Wind-driven optimization \\
TOU & Time of use \\
FRP & Flat rate pricing \\
IBR & Inclined block rate \\
DHP & Day-ahead pricing \\
PS & Pareto sets \\
SG & Smart grid \\
SM & Smart meter \\
GA & Genetic algorithm \\
SFL & Shuffled frog leaping \\
\hline
\end{tabular}

Table 2. Nomenclature.

\begin{tabular}{cc}
\hline$D$ & Total appliances \\
$D_{s}$ & Set of shiftable appliances \\
$D_{c}$ & Set of controllable appliances \\
$D_{n s}$ & Set of non-shiftable appliances \\
$\rho$ & Power rating \\
$\chi$ & Status of appliance \\
$h$ & Time slots \\
$\mu$ & Trial vector \\
$v$ & Mutant vector \\
$U_{j}$ & Upper bound \\
$l_{j}$ & Lower bound \\
$C R$ & Crossover rate \\
$P O P$ & Population \\
$M a x . i t e r$ & Maximum iteration \\
$D_{\alpha}$ & Position of the $\alpha$ search agent \\
$D_{\beta}$ & Position of the $\beta$ search agent \\
$D_{\delta}$ & Position of the $\delta$ search agent \\
$F$ & Scaling factor \\
$A, C$ & Fitness coefficients \\
$\alpha$ & Best search agent \\
$\beta$ & Second best optimal solution \\
$\delta$ & Third best optimal solution \\
\hline
\end{tabular}

\section{Related Work}

In the past few years, a number of optimization techniques in the smart grid has been proposed by researchers in order to achieve a common objective such as cost reduction. Efforts have been made for the economical use of electricity. In this section, existing work on these optimization techniques is presented.

The genetic algorithm (GA) and bacterial foraging algorithm (BFA) were proposed with their hybrid scheme in [9]. Three pricing schemes, RTP, TOU and CPP, were used to evaluate the performance of these algorithms. The main objective of this paper was to achieve PAR minimization and load shifting from on-peak hours to off-peak hours.

In [10], three optimization algorithms, EDE, binary particle swarm optimization (BPSO) and GA, were implemented to achieve cost minimization and load shifting, while carbon emission was reduced by integrating RES. DHP is used as a pricing tariff. The primary concern was not only scheduling of appliances, but also prioritizing their operation according to the consumer's demand. The authors 
ensured grid sustainability by balancing load at the generation and consumptions units. However, they ignored user comfort.

The authors in [11] considered demand response under the corporate sector. In order to manage energy consumption, certain measures were adopted to maintain a balance between production and consumption. Two different pricing schemes were used, such as DHP and RTP. In [12], an optimization model such as GA for balancing electric load was proposed by the authors. They took time horizon $\mathrm{T}$ equal to $24 \mathrm{~h}$. The load profile generator tool was used to calculate energy consumption and the pattern of load in each time horizon. However, user comfort was ignored, and the execution time was compromised.

A generic cost model was proposed by [13]. Certain problems were resolved through an intelligent decision support system (IDSS). IDSS connected to AMI provides quality communication between the consumer and utility. WDO with knapsack (K-WDO) was implemented to achieve the objective function of cost minimization and maximizing user comfort [14]. Min-max constraints were defined for K-WDO. Appliances were categorized according to their type and power ratings. TOU was used as the electricity pricing signal for on-peak and off-peak hours in accordance with user preference; however, PAR and system complexity were compromised.

The ant colony optimization algorithm for optimal power flow (OPF) in the grid was proposed by [15]. The main objective of OPF was to calculate the load of each time period so that energy demand could be satisfied at the user end. Methods used to solve such problems are linear programming (LP), non-linear programming (NLP), mixed-integer linear programming (MILP), mixed integer non-linear programming (MINLP), the Newton method and the interior point method.

Load shifting and balancing were the main objectives of [16]. For this purpose, a multi-agent model was designed in which each user acted as a single agent. The load for each agent was divided into time frames. Power was dispatched for each agent according to a particular time frame. Residential, commercial and industrial users were considered in this paper. In [17], the basic concepts of the EDE algorithm were discussed. An enhanced version of differential evolution was used in which five trial vectors were used instead of one trial vector. A new population was generated using three random vectors. In $\mathrm{EDE}$, the mutant vector was generated, and then, trial vectors were created by comparing fitness with target and mutant to update the population. The differential evolution algorithm (DE) was presented in [18] with different crossover and mutation strategies in order to enhance the performance of the algorithm for scheduling purpose. In contrast to [17], a single trial vector was used to update the population.

In [19], the multi-objective optimization problem was taken into consideration by generating a test on Pareto sets (PS) using DE. The main purpose of this model was to deal with complex PS shapes. This model was called the multi-objective evolutionary algorithm (MOEA). The issue of varying electricity prices was catered by [20], and a forecasting model was proposed based on the hybrid evolutionary approach. These forecasts were calculated for 24 and $168 \mathrm{~h}$ ahead of time. The hybrid evolutionary approach includes particle swarm optimization (PSO) with a neuro-fuzzy logic network in order to eliminate the uncertainty in the market's electricity rates. In [21], the correlation between electricity price and load was developed to alter the energy consumption pattern in slots where the electricity price was high. The multiple input and multiple output model was adopted to formulate the problem with the help of wavelet packet transform (WPT) and generalized mutual information (GMI). Forecasting of electricity prices was performed in order to analyze the pattern of variation. The ant colony optimization algorithm was applied for optimization purposes.

Energy management in the smart grid was presented in [22] using teaching and learning-based optimization (TLBO) and shuffled frog leaping (SFL). Four scenarios were considered with different pricing schemes such as TOU, RTP, CCP and the last one without $\mathrm{n}$ electricity tariff. Scheduling was performed by varying electricity prices in different intervals. Power storage in the case of sensitive load demand from the consumer was discussed in [23]. Virtual power play helped to schedule load and energy consumption ahead of time. For distributed generation of electricity, load demand increased 
simultaneously. To cater to the intensive load demand, the vehicle to grid (V2G) strategy was used. BPSO along with MILP was proposed for balancing the load among multiple distribution units. It involved a complex mathematical formulation to design a model for day-ahead electricity price forecasting. One hundred and eighty distributed units along with 1000 electric vehicle stations were used to perform this evaluation on an experimental basis.

Energy consumption in the residential sector plays an important role in reducing electricity prices and its consumption. Considering this fact, residential appliances were scheduled using an artificial neural network and GA (ANN-GA) scheme in [24]. The scheduling was performed on a single home with four bedrooms on a weekly basis. The objective was to find the best possible solutions out of the total search space. Results were obtained with a $25 \%, 40 \%$ and $10 \%$ reduction in electricity usage from the grid. However, multiple OTIs were not taken into consideration.

In [25], the authors presented DSM techniques for the residential sector. Multiple homes with SM were considered for two-way communication between the consumer and utility. EMC was installed in each home to schedule the appliances. GA, BPSO, WDO and BFOA were applied to evaluate the performance in terms of cost, user comfort and PAR. However, trade-off parameters were not discussed.

A distributed algorithm was proposed by [26] for 2560 households to minimize the payment with reasonable comfort level. Authors in [27] proposed a new heuristic harmony model for load shifting in smart grid, however authors in [28] emphasized on cost minimization. Game theory model was proposed by [29] and [30] with different objective functions as PAR minimization and load shifting.

In the above-mentioned literature, the authors did not get a complete benefit from the smart grid. They minimized PAR or cost, while some authors worked on user comfort. However, the above-mentioned parameters were not catered to by any literature work simultaneously. Furthermore, multiple OTIs were not taken into account. In this research work, the cost and PAR minimization with affordable waiting time are considered simultaneously to achieve the objective of efficient power usage in the residential sector. A brief summary of related work with its limitations is given in Table 3.

Table 3. Summarized related work.

\begin{tabular}{|c|c|c|c|}
\hline Features & Techniques & Targets Achieved & Limitations \\
\hline MILP & Optimal scheduling of domestic appliances [5] & Minimize cost & $\begin{array}{l}\text { Ignored user } \\
\text { comfort }\end{array}$ \\
\hline Greedy algorithm & $\begin{array}{l}\text { Heuristic optimization of consumer electricity } \\
\text { costs using a generic cost model [13] }\end{array}$ & $\begin{array}{l}\text { Minimized user } \\
\text { frustration and cost }\end{array}$ & $\begin{array}{l}\text { PAR is ignored, } \\
\text { system complexity } \\
\text { increased }\end{array}$ \\
\hline Multi-agent model & $\begin{array}{l}\text { Demand-side management of the smart grid: } \\
\text { load shifting and incentives [16] }\end{array}$ & $\begin{array}{l}\text { Load shifting and } \\
\text { cost minimization }\end{array}$ & $\begin{array}{l}\text { User comfort is } \\
\text { compromised }\end{array}$ \\
\hline $\begin{array}{c}\text { BPSO and } \\
\text { neuro-fuzzy logic }\end{array}$ & $\begin{array}{l}\text { Electricity price forecasting by a hybrid } \\
\text { evolutionary-adaptive methodology [21] }\end{array}$ & $\begin{array}{l}\text { Electricity market } \\
\text { price forecasting } \\
\text { using mean } \\
\text { absolute percentage } \\
\text { error (MAPE) }\end{array}$ & $\begin{array}{l}\text { Trade-off between } \\
\text { MAPE and } \\
\text { computational time }\end{array}$ \\
\hline $\begin{array}{l}\text { Multiple input } \\
\text { multiple output } \\
\text { model (MIMO) }\end{array}$ & $\begin{array}{l}\text { Simultaneous day-ahead forecasting of electricity } \\
\text { price and load in smart grids [22] }\end{array}$ & $\begin{array}{l}\text { Load and price } \\
\text { signal forecasting }\end{array}$ & $\begin{array}{l}\text { Real-time } \\
\text { forecasting is not } \\
\text { considered }\end{array}$ \\
\hline $\begin{array}{l}\text { Teaching and } \\
\text { learning-based } \\
\text { optimization } \\
\text { (TLBO) and shuffled } \\
\text { frog leaping (SFL) }\end{array}$ & $\begin{array}{l}\text { The optimization of demand response programs } \\
\text { in smart grids [23] }\end{array}$ & Cost optimization & RES not integrated \\
\hline
\end{tabular}


Table 3. Cont.

\begin{tabular}{|c|c|c|c|}
\hline Features & Techniques & Targets Achieved & Limitations \\
\hline PSO and MILP & $\begin{array}{l}\text { A multi-objective model for the day-ahead } \\
\text { energy resource scheduling of a smart grid with } \\
\text { high penetration of sensitive loads [24] }\end{array}$ & $\begin{array}{l}\text { Virtual power play } \\
\text { scheduling }\end{array}$ & $\begin{array}{l}\text { Requirements of the } \\
\text { customers for } \\
\text { reliable power grids } \\
\text { is not considered }\end{array}$ \\
\hline MIMO & $\begin{array}{c}\text { Novel hybrid algorithm for electricity price and } \\
\text { load forecasting in smart grids with } \\
\text { demand-side management [25] }\end{array}$ & $\begin{array}{l}\text { Electricity price and } \\
\text { load forecasting }\end{array}$ & $\begin{array}{l}\text { Computational time } \\
\text { is not practical }\end{array}$ \\
\hline GWO & $\begin{array}{l}\text { Economic dispatch using the hybrid gray wolf } \\
\text { optimizer [31] }\end{array}$ & $\begin{array}{l}\text { Solving non-linear } \\
\text { economic load } \\
\text { dispatch problems }\end{array}$ & $\begin{array}{l}\text { The user has to } \\
\text { come up with ways } \\
\text { of handling the } \\
\text { constraints }\end{array}$ \\
\hline ANN-GA & $\begin{array}{l}\text { ANN-GA smart appliance scheduling for } \\
\text { optimized energy management in the domestic } \\
\text { sector [32] }\end{array}$ & $\begin{array}{l}\text { Reduction in grid } \\
\text { energy usage }\end{array}$ & $\begin{array}{l}\text { Cannot be applied } \\
\text { to different building } \\
\text { types involving a } \\
\text { higher number of } \\
\text { appliances }\end{array}$ \\
\hline $\begin{array}{l}\text { Game theory } \\
\text { algorithm (GTFT) }\end{array}$ & $\begin{array}{c}\text { A demand response modeling for residential } \\
\text { consumers in a smart grid environment using a } \\
\text { game theory-based energy scheduling } \\
\text { algorithm [33] }\end{array}$ & $\begin{array}{l}\text { Scheduling the } \\
\text { appliances using the } \\
\text { game theory } \\
\text { strategy and PAR } \\
\text { reduction }\end{array}$ & RES not integrated \\
\hline $\begin{array}{l}\text { MILP and heuristic } \\
\text { algorithms }\end{array}$ & $\begin{array}{l}\text { Load scheduling for household energy } \\
\text { consumption optimization [34] }\end{array}$ & Load balancing & $\begin{array}{l}\text { Cost minimization } \\
\text { is not considered }\end{array}$ \\
\hline MINLP & $\begin{array}{l}\text { Optimal scheduling of household appliances for } \\
\text { demand response [35] }\end{array}$ & $\begin{array}{l}\text { Cost reduction is } \\
\text { achieved }\end{array}$ & PAR is ignored \\
\hline GWO and ILP & $\begin{array}{l}\text { Grey wolf optimization applied to economic load } \\
\text { dispatch problems [36] }\end{array}$ & $\begin{array}{l}\text { Load dispatching in } \\
\text { off-peak hours }\end{array}$ & $\begin{array}{l}\text { Solved economic } \\
\text { load dispatch (ELD) } \\
\text { problems in the } \\
\text { current study }\end{array}$ \\
\hline
\end{tabular}

\section{System Model}

The basic architecture of our proposed scheme is elaborated in Figure 1. A single smart home with 17 appliances is taken into consideration [37]. Each appliance has different power ratings. Appliances are scheduled to achieve the objective function. The HEM system is integrated for two-way communication between consumer and utility. Different electricity pricing signals are defined by the utility such as RTP, TOU, CPP, DHP, variable time pricing and IBR. Time slots in which load demand from the consumer reaches the maximum value are called peak hours. Electricity prices are usually high in on-peak hours.

A bidirectional flow is presented in the model. First, electricity price is sent to the user. Considering the electricity rates, EMC decides which appliances should be turned on. Heavy appliances cannot be switched on in peak hours. EMC is integrated to induce automation in order to reduce electricity bills. After the final decision, the load demand is dispatched to the utility through SM, and ultimately, the requested power is sent to the consumer via the utility. RTP and $\mathrm{CPP}$ schemes for $24 \mathrm{~h}$ are given in Figure 2a,b. The data for these two pricing schemes are collected from $[38,39]$. 


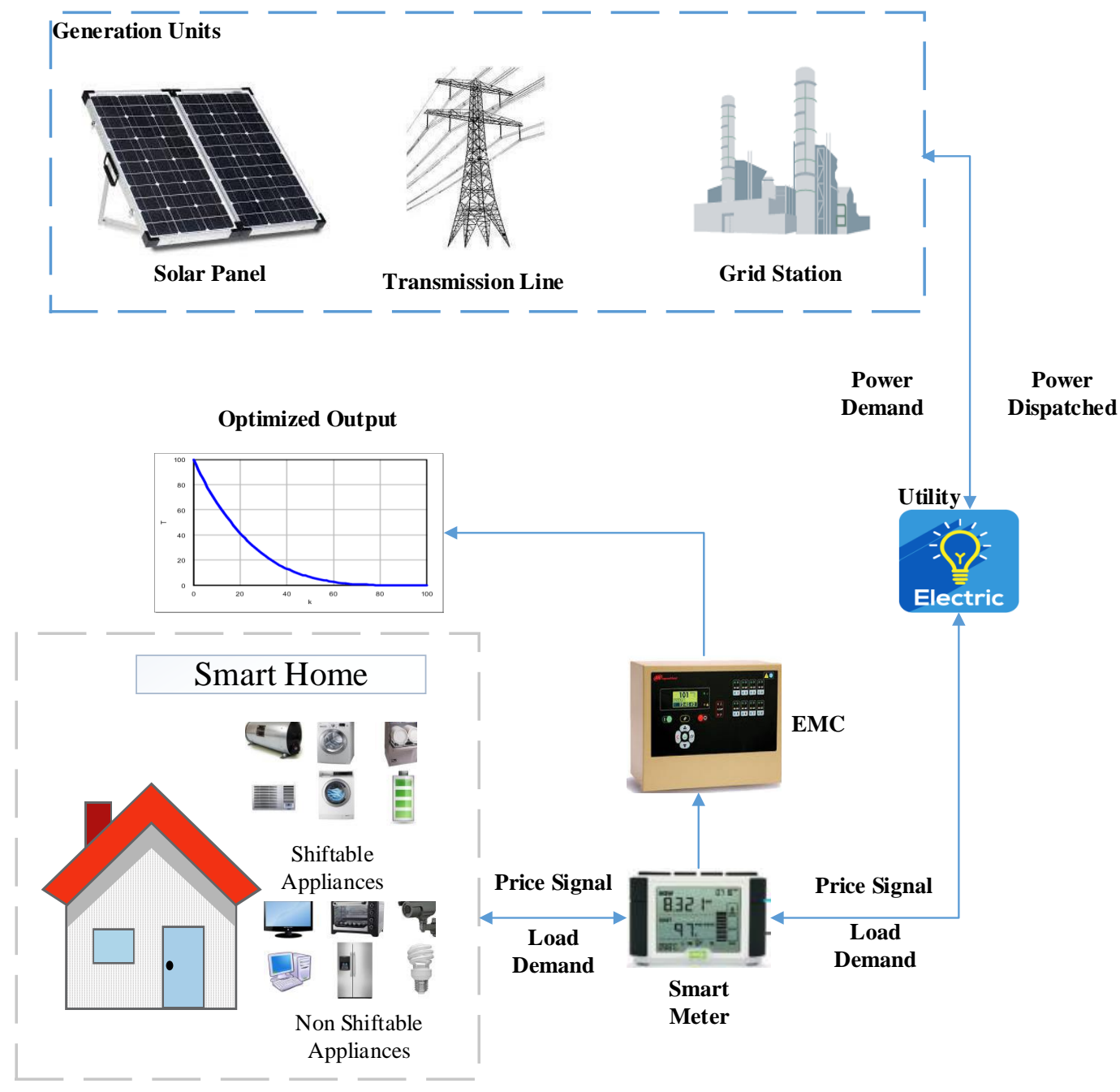

Figure 1. Proposed system model.

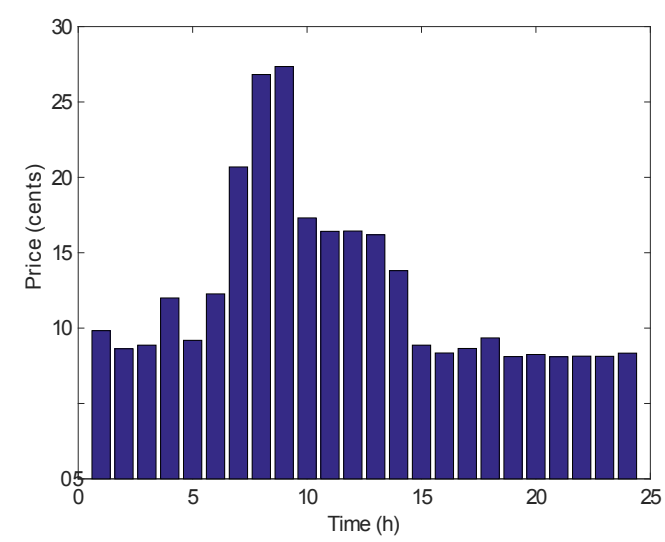

(a) Real-time pricing (RTP)

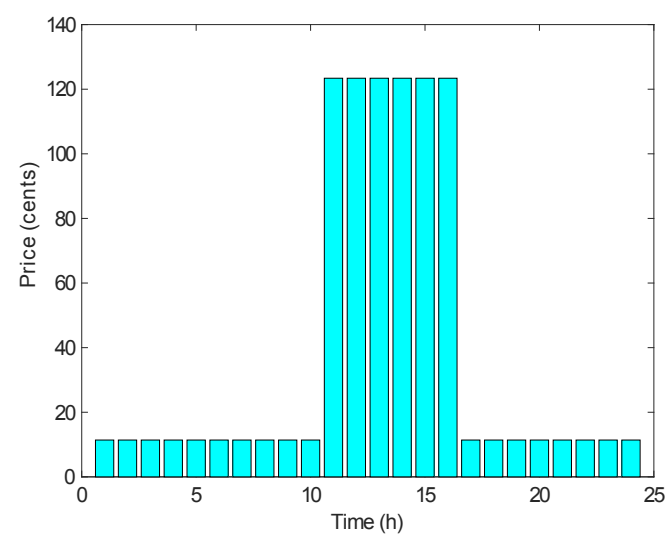

(b) Critical peak pricing (CPP)

Figure 2. Pricing schemes.

\subsection{Classification of Appliances}

Appliances are categorized on the basis of their operational behavior and energy consumption pattern. Details of each classification are given below. 


\subsubsection{Shiftable Appliances}

Such appliances are also called deferrable appliances. They can be shifted to any time slot, but cannot be interrupted during their operational time. Once their operation is started, they cannot be stopped until the time slot reaches zero. Washing machines and dishwashers are uninterpretable appliances. The total number of appliances is given by $D$. Shiftable appliances are a subset of total appliances. From Equation (2), $P \varepsilon D_{s}$ represents the set of shiftable appliances. The power rating of each appliance is represented by $\rho$ and $\chi v_{P}(h)$, where $t \epsilon T$ shows the power rating and status of $D_{s}$ appliance at a particular time slot. Equation (3) represents the cases as zero when the appliance is OFF and one when the appliance is $\mathrm{ON}$.

\subsubsection{Controllable Appliances}

Such appliances are also called interruptible appliances. The operational time of these appliances cannot be changed; for example, lightning, air conditioner and heating system. $D_{c}$ is the set of controllable appliances. The cost for controllable appliances is given in Equation (2).

\subsubsection{Non-Shiftable Appliances}

These appliances are also called base appliances. Energy consumption and operational time cannot be changed for such appliances. Televisions, refrigerators and telephones are classified as non-shiftable appliances. From Equation (2), $P \varepsilon D_{n s}$ is the set of non-shiftable appliances.

$$
\begin{gathered}
P=D_{s}, D_{n s}, D_{c} \\
P=\sum_{h=1}^{H} \sum_{P \varepsilon D} \rho_{P} \times \chi v_{P}(h) \\
\chi v_{P}(h)= \begin{cases}1, & \text { if appliance is } \mathrm{ON} \\
0, & \text { otherwise }\end{cases}
\end{gathered}
$$

Classification and the power rating of each appliance are given in Table 4.

Table 4. Parameters of appliances.

\begin{tabular}{cccccc}
\hline \multirow{2}{*}{ Appliance Class } & Appliance & $\begin{array}{c}\text { Power } \\
\text { Rating (kWh) }\end{array}$ & $\begin{array}{c}\text { Earliest Starting } \\
\text { Time (h) }\end{array}$ & $\begin{array}{c}\text { Finishing } \\
\text { Time (h) }\end{array}$ & LOT (h) \\
\hline \multirow{5}{*}{ Shiftable Appliances } & Washing Machine & 1.4 & 6 & 10 & $1-3$ \\
& Dish Washer & 1.32 & 15 & 20 & $1-3$ \\
& Hair Straightener & 0.055 & 18 & 8 & $1-2$ \\
& Hair Dryer & 1.8 & 18 & 8 & $1-2$ \\
& Microwave & 1.2 & 18 & 8 & $3-5$ \\
& Telephone & 0.005 & 9 & 17 & $1-24$ \\
& Computer & 0.15 & 18 & 24 & $6-12$ \\
& Oven & 2.4 & 6 & 10 & $1-3$ \\
& Cooker & 0.225 & 18 & 24 & $2-4$ \\
& Iron & 2.4 & 18 & 24 & $3-5$ \\
& Toaster & 0.8 & 9 & 17 & $1-2$ \\
& Kettle & 2 & 18 & 8 & $1-2$ \\
& Printer & 0.011 & 18 & 24 & $1-2$ \\
\hline \multirow{2}{*}{ Non-Shiftable Appliances } & Television & 0.083 & 9 & 17 & $6-12$ \\
& Refrigerator & 1.666 & 1 & 24 & $1-24$ \\
\hline \multirow{2}{*}{ Controllable Appliances } & Air Conditioner & 1.14 & 16 & 24 & $6-8$ \\
& Lightning & 0.1 & 1 & 24 & $12-20$ \\
\hline
\end{tabular}




\section{Proposed Scheme}

In this section, different meta-heuristic optimization algorithms are discussed for DSM. These techniques are performed on a single home with 17 appliances. Each appliance has different power ratings according to their energy consumption patterns. There are four basic steps of electricity such as generation, transmission, distribution and consumption. Electricity is consumed by the residential, corporate and industrial sector. However, our main goal is to achieve efficient power scheduling in the residential sector. For DSM in the residential area, different optimization techniques have been proposed by many researchers. In this regard, we have proposed an optimization technique, HGWDE, which is a hybrid of two different meta-heuristics: EDE and GWO to optimize the electricity consumption. All three techniques are implemented to evaluate the performance of our proposed scheme with respect to existing schemes.

\section{1. $E D E$}

EDE is an upgraded form of DE, which was proposed by Storn in 1995 for the very first time. It is a population-based algorithm where the initial population is randomly generated. The four main steps of EDE include initial generation of the population, mutation, crossover and selection. The population is generated randomly using Equation (4).

$$
X_{i, j}=l_{j}+\left(\text { rand } \times\left(U_{j}-l_{j}\right)\right)
$$

Create a random function to generate three vectors $x_{r 1}, x_{r 2}, x_{r 3}$ in order to form a mutant vector. The first vector is declared as the target vector. The mutant vector is created according to Equation (5) given below:

$$
V_{i, G+1}=x_{r 1, G}+F\left(x_{r 2, G}-x_{r 3, G}\right)
$$

where $F$ is a scaling factor. After forming the mutant vector, three trial vectors are created. Then, the best trial vector is selected to compare it with the target vector, so that the generation can be populated with the best vector. The first three trial vectors are created using Equations (6)-(8).

$$
\begin{aligned}
& U_{j, i, G+1}= \begin{cases}V_{j, i, G+1} & \text { if } \operatorname{randb}(j) \leq 0.3 \\
x_{j, i, G} & \text { Otherwise }\end{cases} \\
& U_{j, i, G+1}= \begin{cases}V_{j, i, G+1} & \text { if randb }(j) \leq 0.6 \\
x_{j, i, G} & \text { Otherwise }\end{cases} \\
& U_{j, i, G+1}= \begin{cases}V_{j, i, G+1} & \text { if randb }(j) \leq 0.9 \\
x_{j, i, G} & \text { Otherwise }\end{cases}
\end{aligned}
$$

The fourth and fifth trial vectors are created using Equations (9) and (10).

$$
\begin{gathered}
U_{j, i, G+1}=\operatorname{randb}(j) \cdot x_{j, i, G} \\
U_{j, i, G+1}=\operatorname{randb}(j) \cdot v_{j, i, G}+(1-\operatorname{randb}(j)) \cdot x_{j, i, G}
\end{gathered}
$$

The pseudocode for EDE is presented in Algorithm 1. Max.iter represents the maximum iterations; $P O P$ is the total population, which is the number of possible solutions in the case of HEMS; and $h$ is the total time slots. $C R$ is the crossover ratio, which is taken as 0.3, 0.6 and 0.9. $v, \mu$ and $x$ are the mutant, trial and target vectors. EDE in terms of HEM is shown in Table 5. 
Table 5. Enhanced differential evolution (EDE) mapping on Home energy management (HEM).

\begin{tabular}{ccc}
\hline EDE Parameters & HEM Parameters & Values \\
\hline Population & Possible solution & 50 \\
Number of dimensions & Number of appliances & 17 \\
Gradient of problem & Scheduling & vary \\
\hline
\end{tabular}

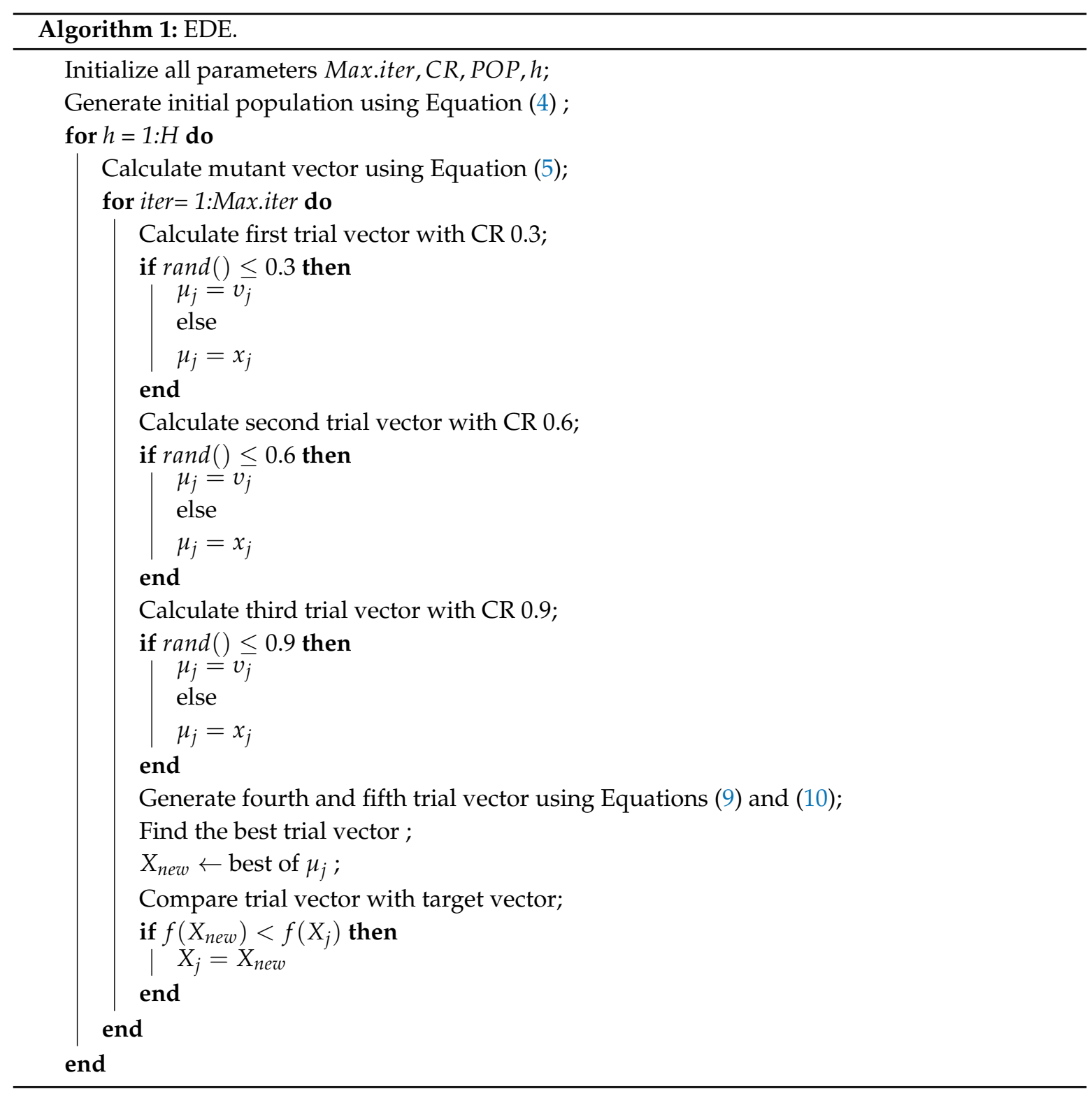

\subsection{GWO}

GWO is a meta-heuristic optimization algorithm, inspired by the hunting nature and hierarchical leadership of wolves. There are four levels of leadership, i.e., alpha $\alpha$, beta $\beta$, delta $\delta$ and gamma $\gamma$. Alpha is considered as the most intelligent leaders of the group; they are responsible for guiding other wolves on hunting strategies. After alpha, there comes beta and delta in the hierarchical level, and gamma is the weakest members of the group. Hence, gamma cannot be considered for leadership 
qualities. In HEM, alpha $\alpha$ is taken as the fittest member to achieve the objective function of cost minimization. The initial population is created randomly using Equation (11):

$$
X(i, j)=\operatorname{rand}(P O P, D)
$$

where $P O P$ represents the total population of gray wolves and $D$ is the total number of appliances. Coefficients $A$ and $C$ are calculated to evaluate the objective function (distance from prey) of each search agent.

\subsubsection{Encircling Prey}

Gray wolves encircle a prey before hunting. For the mathematical formulation of encircling behavior of gray wolves, the following equations are considered from [40].

$$
\begin{gathered}
X(t+1)=X_{p}(t)-A \times D \\
D=\left|C \times X_{p(t)}-X(t)\right|
\end{gathered}
$$

$X_{p}$ represents the position of prey, while $X$ is the position of the gray wolf at the $t_{t h}$ iteration, which is given by Equation (12). The vectors $A$ and $C$ are calculated according to Equations (14) and (15):

$$
\begin{gathered}
\vec{A}=2 \vec{a} \times r_{1}-\vec{a} \\
\vec{C}=2 \times \overrightarrow{r_{2}}
\end{gathered}
$$

where $\overrightarrow{r_{1}}$ and $\overrightarrow{r_{2}}$ are random vectors within the range of $[0,1]$. After multiple iterations, the value of $a$ is reduced from two to zero. The value of $C$ is taken randomly between zero and two, which is used to define the weight for the attractiveness of prey.

\subsubsection{Hunting}

Hunting is mainly guided by $\alpha$, while $\beta$ and $\delta$ are the secondary participants. They follow the lead of $\alpha$, which has the best knowledge about the position of prey. The first three best solutions are obtained so that other members of the group such as gamma $\gamma$ update its position according to the best solution. The position of wolves is updated according to Equation (16).

$$
\overrightarrow{X_{t+1}}=\frac{\overrightarrow{x_{1}}+\overrightarrow{x_{2}}+\overrightarrow{x_{3}}}{3}
$$

$\overrightarrow{x_{1}}, \overrightarrow{x_{2}}$ and $\overrightarrow{x_{3}}$ are determined by using Equations (17)-(19).

$$
\begin{aligned}
& \overrightarrow{x_{1}}=\overrightarrow{x_{\alpha}}-\overrightarrow{A_{1}} \times\left(\overrightarrow{d_{\alpha}}\right) \\
& \overrightarrow{x_{2}}=\overrightarrow{x_{\beta}}-\overrightarrow{A_{2}} \times\left(\overrightarrow{d_{\beta}}\right) \\
& \overrightarrow{x_{3}}=\overrightarrow{x_{\delta}}-\overrightarrow{A_{3}} \times\left(\overrightarrow{d_{\delta}}\right)
\end{aligned}
$$

$\overrightarrow{x_{\alpha}}, \overrightarrow{x_{\beta}}$ and $\overrightarrow{x_{\delta}}$ are the best solutions obtained at the $t_{t h}$ iteration; $\overrightarrow{A_{1}}, \overrightarrow{A_{2}}, \overrightarrow{A_{3}}$ are determined using Equation (14), while $\overrightarrow{D_{\alpha}}, \overrightarrow{D_{\beta}}, \overrightarrow{D_{\delta}}$ are determined using Equations (20)-(22):

$$
\begin{aligned}
& \overrightarrow{D_{\alpha}}=\overrightarrow{C_{1}} \times \overrightarrow{x_{\alpha}}-\vec{x} \\
& \overrightarrow{D_{\beta}}=\overrightarrow{C_{2}} \times \overrightarrow{x_{\beta}}-\vec{x} \\
& \overrightarrow{D_{\delta}}=\mid \overrightarrow{C_{3}} \times \overrightarrow{x_{\delta}}-\vec{x}
\end{aligned}
$$


where $C_{1}, C_{2}$ and $C_{3}$ are calculated using Equation (15). The last step is the gradation of variable $a$; it controls the trade-off between exploration and exploitation by taking the value from two to zero in each iteration as shown in Equation (23).

$$
a=2-t \frac{2}{\text { Max.iter }}
$$

Equation (24) shows the objective function, which is calculated as the power rating of each appliance multiplied by the status of the appliance.

$$
\text { Fitness }=\rho_{D} \times \chi v_{D}(h)
$$

From Algorithm 2, Max.iter represents the maximum iterations, $P O P$ is the total population, $D$ is the number of appliances and fitness is the objective function. $\alpha$ is considered as the best solution or participant in the hunting behavior, while $\beta$ and $\delta$ are the second and third optimal solutions, respectively.

The fitness function is compared with the fitness of $\alpha, \beta$ and $\delta$ to evaluate the best hunting leader. Their final positions are updated according to Equations (20)-(22).

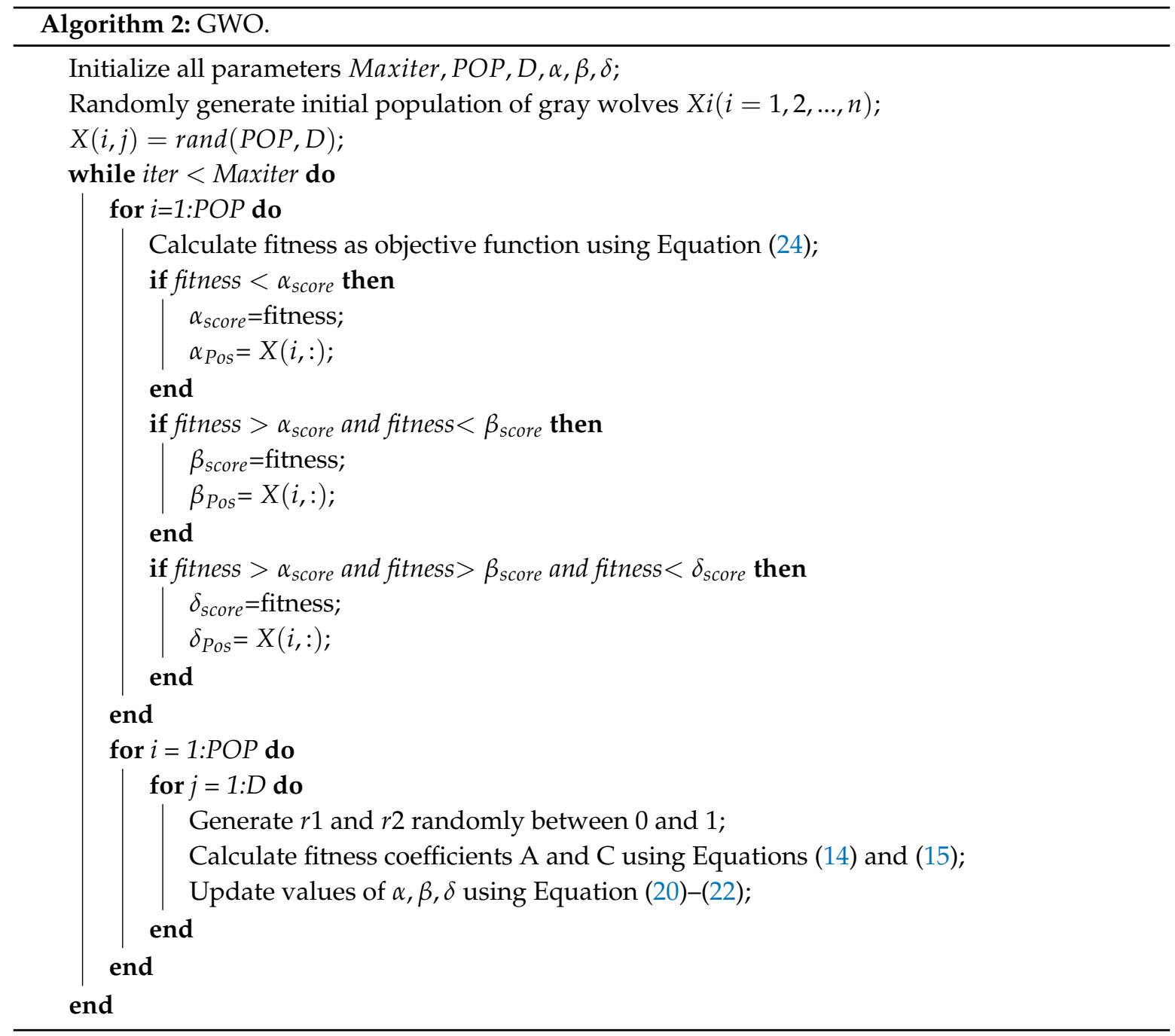




\subsection{HGWDE}

In this section, our proposed scheme is discussed in detail. In EDE, the new population is generated using four steps: initialization, mutation, crossover and selection. The population is updated by selecting the best trial vector out of five vectors and then comparing it with the target vector. The selection procedure of EDE is effective as it considers the best trial vector from all the available vectors. In GWO, there are three basic steps: encircling prey, hunting and updating the position of wolves within the pack. $\alpha$ is considered as the leader. All the search agents of the pack update their position according to $\alpha$. In GWO, their is no comparison of $\alpha$ with $\beta$ and $\delta$. It might be possible that $\beta$ and $\delta$ are much closer to the prey as compared to $\alpha$. In order to make a clear comparison among all the search agents, crossover from EDE is performed. After selection of the best search agent, updating the position of search agents is performed according to GWO. HGWDE is adopted as it has the best features of EDE and GWO.

The detailed steps of HGWDE are presented in Algorithm 3. The steps of HGWDE are initialization, encircling prey, selection of best search agent and updating the position. A random population of wolves $\mathrm{Xi}(i=1,2, \ldots, n)$ is generated using Equation (2). Selection is performed according to the steps given in Algorithm 3. A mutant vector $v$ is created by using three random vectors according to Equation (5). $\alpha, \beta$ and $\delta$ are initialized as three vectors. The fitness of $v$ and $\alpha, \beta, \delta$ is calculated by using Equation (24). The crossover is performed by using the equations given below:

$$
\begin{aligned}
& \alpha_{\text {new }}=\left\{\begin{array}{lc}
v_{j} & \text { if } \text { fitness of } v_{j} \leq \alpha \\
\alpha & \text { Otherwise }
\end{array}\right. \\
& \beta_{\text {new }}=\left\{\begin{array}{lc}
v_{j} & \text { if } \text { fitness of } v_{j} \leq \beta \\
\beta & \text { Otherwise }
\end{array}\right. \\
& \delta_{\text {new }}=\left\{\begin{array}{lc}
v_{j} & \text { if } \text { fitness of } v_{j} \leq \delta \\
\delta & \text { Otherwise }
\end{array}\right.
\end{aligned}
$$

After selection, the position of search agents is updated relatively according to the steps of GWO, which are given in Equation (16). Mapping of HGWDE parameters with HEM is given in Table 6.

Each step of Algorithm 3 is discussed below in detail. In Step 1, the proposed algorithm starts by initializing the required parameters. The population is generated randomly in Step 2. After population generation, the counter is set to maximum iterations. Crossover is performed by comparing the fitness of the mutant vector with $\alpha, \beta, \delta$ using EDE. Update positions of search agents using GWO. The last step is to repeat until the termination criteria are satisfied.

Table 6. Hybrid gray wolf differential evolution (HGWDE) mapping on HEM.

\begin{tabular}{ccc}
\hline HGWDE Parameters & HEM Parameters & Values \\
\hline Population & Possible solution & 50 \\
Wolfs in each pack & Appliances & 17 \\
Minimum distance from prey & Min (cost) & vary \\
Status of leader & status of appliance & 1 or 0 \\
\hline
\end{tabular}




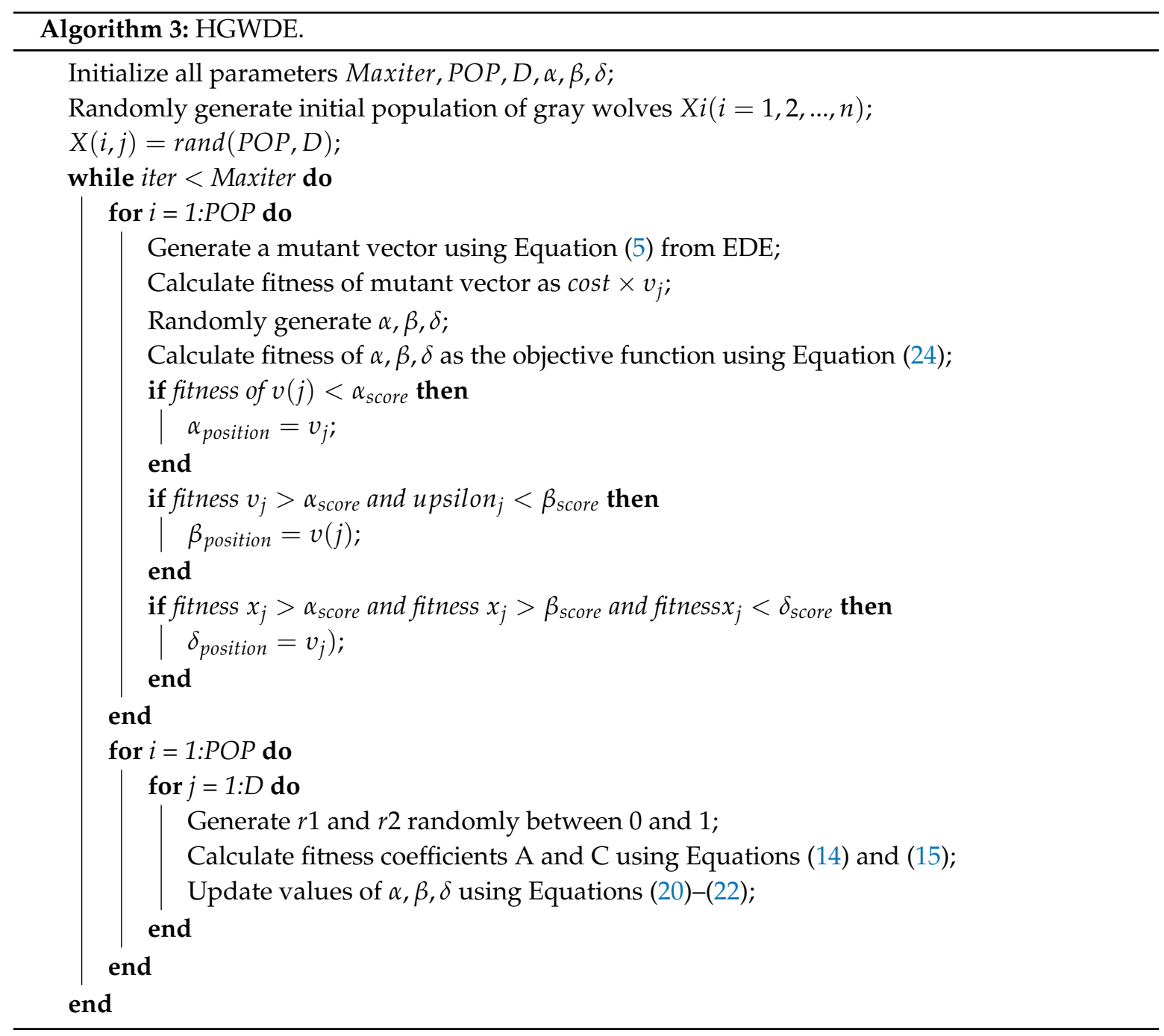

\section{Simulation and Results}

In this section, simulation results for a single smart home are shown to evaluate the performance of our proposed scheme using RTP and CPP. Results for cost and PAR reduction are shown for different OTIs. EMC is installed inside a home for scheduling the appliances according to the price tariff defined by the utility. We consider different time horizons through variable OTIs as $\mathrm{T}=24,48$ and 96 time slots. Data for appliances such as LOT, OTI, early starting-finish time and power rating of each appliance are taken from [37]. Results are shown for each OTI by comparing the performance of existing techniques with our proposed hybrid scheme.

\subsection{Cost}

\subsubsection{Cost Using RTP}

Simulations are performed for different OTIs (15, 30 and $60 \mathrm{~min}$ ) for evaluating the cost parameter of the proposed scheme. Cost is calculated in terms of kWh. Our proposed hybrid scheme HGWDE is implemented to reduce cost as compared to GWO and EDE. Appliances are scheduled for sustaining coordination among electricity price and the pattern of consumption in a particular slot of a day. Our main goal is to shift load from on-peak hours to off-peak hours so that the electricity bill can be reduced.

The energy consumption pattern for all implemented optimization techniques with OTI as $15 \mathrm{~min}$ is shown in Figure 3a. The cost for each time slot is given for the unscheduled and scheduled scenario. 
The presence of peaks can be observed in the unscheduled case. This means that prices are high in these particular time slots. However, peaks are eliminated through scheduling. Although variation in the cost pattern of GWO and HGWDE is minor, our proposed scheme outperforms both GWO and EDE in terms of peak reduction. Figure $3 \mathrm{~b}$ elucidates the cost pattern for each time slot with OTI $30 \mathrm{~min}$. GWO has the highest cost at the starting intervals, while HGWDE shows minimum cost throughout the day. Similarly, Figure $3 \mathrm{c}$ represents the similar pattern of cost reduction for our proposed scheme as compared to the rest of the optimization schemes. HGWDE has minimal cost, which means that our proposed scheme can successfully reduce the electricity bill, which is our main objective.

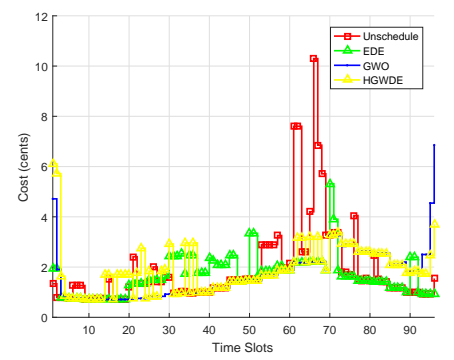

(a) Cost 15 min OTI

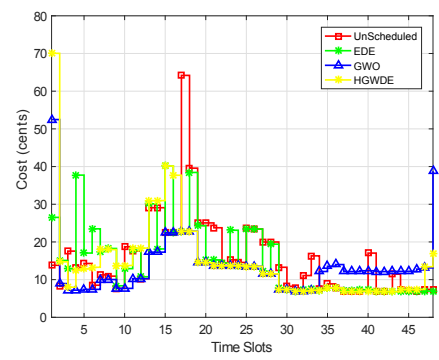

(b) Cost 30 min OTI

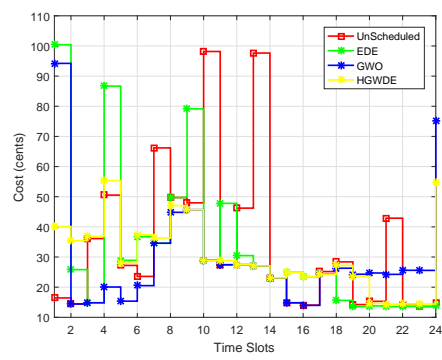

(c) Cost $60 \mathrm{~min}$ OTI

Figure 3. Cost per time slot for RTP.

It has been observed from Figure 4 that the overall cost of our proposed scheme is reduced as compared to other techniques, such as EDE and GWO.

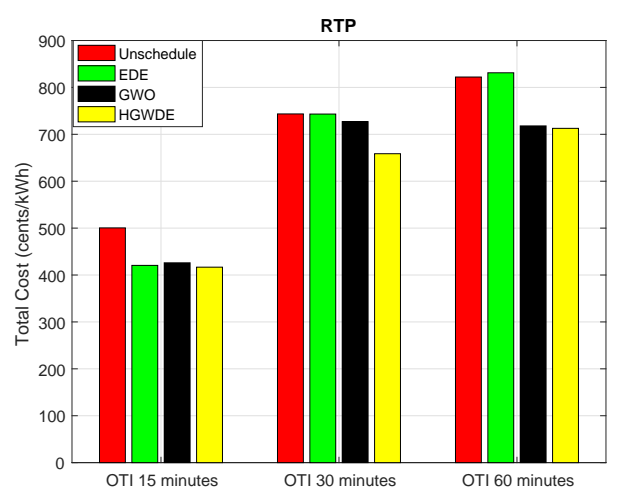

(a) Cost using RTP

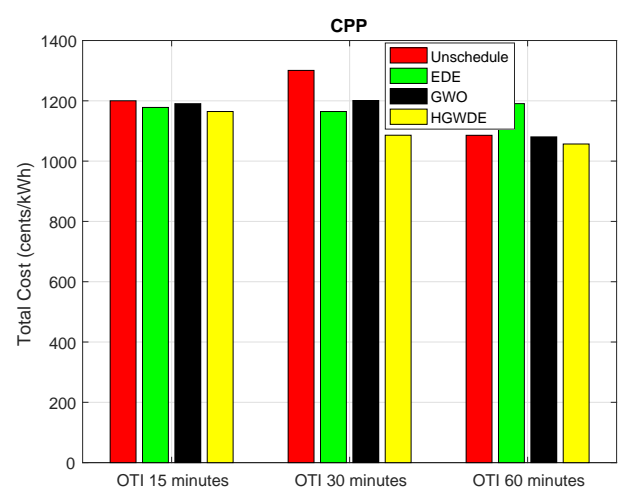

(b) Cost using CPP

Figure 4. Total cost after scheduling using RTP and CPP.

Figure 4 a represents the total cost under RTP. For 15-min OTI, unscheduled cost is recorded as 500.4826 cents. However, after applying scheduling schemes, EDE and GWO, total cost is reduced to 420.5380 cents and 426.0507 cents, respectively. Our proposed scheme successfully achieved cost reduction up to 416.7467 cents, which is the maximum discount as compared to other scheduling schemes. A similar pattern of cost reduction can be observed for 30- and 60-min OTI.

\subsubsection{Cost using CPP}

Cost minimization is the main objective of implementing optimization schemes for DSM. Minimization of the electricity bill is evaluated using different pricing schemes. The cost pattern for variable OTIs using CPP is shown in Figure 5. Figure 5a shows the cost stairs for 15-min OTI. In CPP, generally, the electricity price remains the same for the whole year except critical peak periods 
where the price reaches its peak value [41]. A critical period can be observed from 40-65 time slots. For the unscheduled case, the maximum peak is generated at 181.55 cents. More precisely, after scheduling, 83.05 cents have been saved. Figure $5 \mathrm{~b}$ represents the cost stairs for 30 -min OTI. Variation in cost is represented for 48 time slots. The pattern of cost is exactly the same as we have observed in Figure 5a. In the case of HGWDE, no peaks are created except at the start of the day, which is about 56 cents. In Figure 5c, the cost for 60-min OTI is presented. The maximum peak for the unscheduled scenario reaches up to 765.5 cents, which is reduced to 202.45 cents after scheduling with the hybrid scheme. This means that an efficient scheduling has been performed by minimizing the cost up to a significant level. Total cost for all implemented optimization schemes is shown in Figure 4b. For 15-min OTI, total unscheduled cost is calculated as 1300.890 cents, which is reduced to 1085.90 cents after scheduling has been performed using HGWDE. It can be observed that the our proposed scheme outperforms both EDE and GWO in terms of total cost. Reduction in cost for 30- and 60-min OTI is also shown in Figure 4b. A brief comparison of cost under different OTIs using RTP and CPP is given in Table 7.

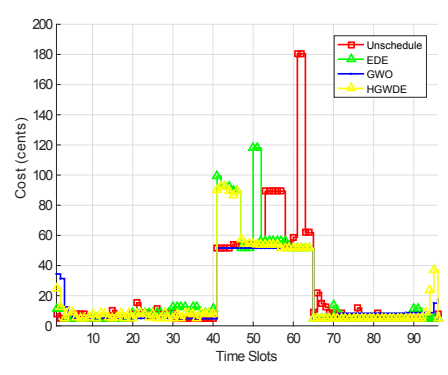

(a) Cost 15-min OTI

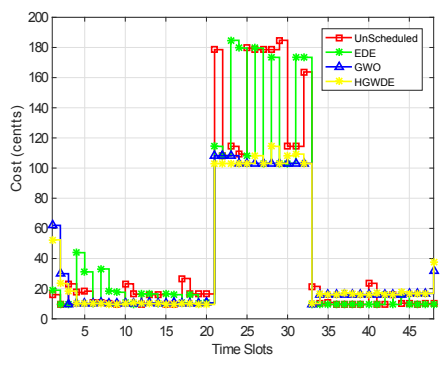

(b) Cost 30-min OTI

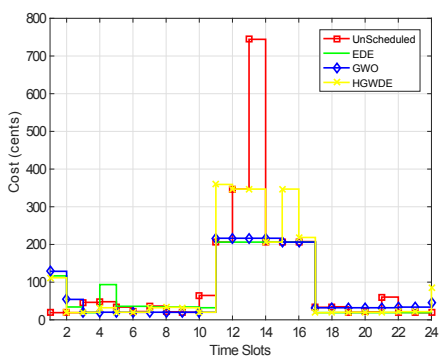

(c) Cost 60-min OTI

Figure 5. Cost per time slot for CPP.

Table 7. Cost Comparison of Different Techniques for $24 \mathrm{~h}$.

\begin{tabular}{ccccccc}
\hline \multirow{2}{*}{ Techniques } & \multicolumn{3}{c}{ Cost (Cents) Using RTP } & \multicolumn{3}{c}{ Cost (Cents) Using CPP } \\
\cline { 2 - 7 } & $\mathbf{1 5} \mathbf{~} \mathbf{~ i n}$ & $\mathbf{3 0} \mathbf{~} \mathbf{~ i n}$ & $\mathbf{6 0} \mathbf{~} \mathbf{m i n}$ & $\mathbf{1 5} \mathbf{~ m i n}$ & $\mathbf{3 0} \mathbf{~ m i n}$ & $\mathbf{6 0} \mathbf{~}$ in \\
\hline Unscheduled & 500.4826 & 743.4876 & 822.1562 & 1200.1562 & 1300.890 & 1085.648 \\
EDE & 420.5380 & 743.1959 & 831.2135 & 1178.0462 & 1164.490 & 1190.690 \\
GWO & 426.0507 & 727.1436 & 717.9405 & 1190.5123 & 1200.96 & 1080.409 \\
HGWDE & 416.7467 & 658.6506 & 712.7298 & 1164.490 & 1085.90 & 1056.7890 \\
\hline
\end{tabular}

\subsection{Energy Consumption}

\subsubsection{Load Using RTP}

Energy consumed in each time slot for different OTIs is shown in Figure 6. The energy consumption pattern for 15-min OTI is given in Figure 6a. It can be observed that at the start and end of the day, prices are relatively low; that is why load is shifted to these time slots. In such a way, load curtailment is performed efficiently by our proposed hybrid scheme.

Figure $6 \mathrm{~b}$ represents the load pattern for 30-min OTI. The energy consumption pattern in HGWDE shows the optimal results as compared to GWO and EDE. The overall pattern by HGWDE shows that the load peaks are eliminated in order to reduce the cost. EDE and GWO also show peak reduction as compared to the unscheduled case, but the proposed scheme outperformed the rest of the optimization techniques that have been used in our research work.

The load pattern for 60-min OTI is shown in Figure 6c. In RTP, prices are low during the start and end of the day. That is why most of the load is shifted to these hours. In the evening, from 3-7 p.m., prices are maximum, so minimal energy is being consumed to reduce the cost. Load shifting affects 
user comfort as the user has to wait for some time in order to switch on a particular appliance, as there is always a trade-off between cost and user comfort.

For 15-min OTI, total energy consumption is recorded as $56.3107 \mathrm{kWh}$, which is the same for the unscheduled and scheduled scenario. For 30-min OTI, load is recorded as $57.7655 \mathrm{kWh}$. Similarly, for 60-min OTI, total load is recorded as $64.5660 \mathrm{kWh}$.

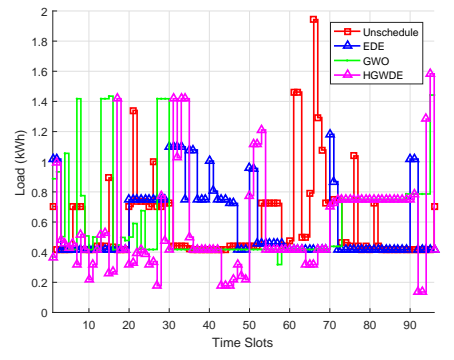

(a) Load 15-min OTI

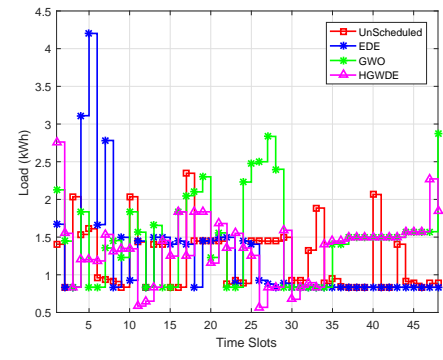

(b) Load 30-min OTI

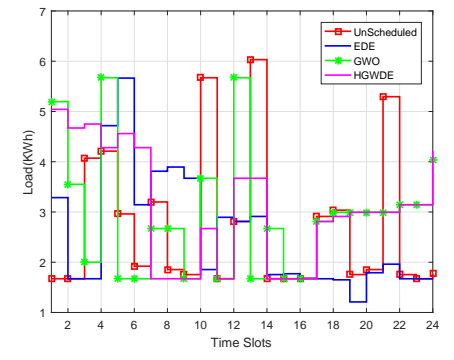

(c) Load 60-min OTI

Figure 6. Load per time slot for RTP.

\subsubsection{Load Using CPP}

In this section, the performance of the proposed scheme is evaluated under CPP with multiple OTIs. Load stairs for multiple OTIs using different optimization schemes are shown in Figure 7. Figure 7a shows the load stairs for 96 time slots. For our proposed scheme, load is mostly shifted to the time slots where electricity prices are low. In critical peak pricing, prices are constant at the start and end of the day, while the critical peak period starts from 40-65 time slots as shown in Figure $2 \mathrm{~b}$. Load shifting in GWO and HGWDE is very much similar, except the starting peak of GWO is much higher than GWO. For 30-min OTI, peaks are eliminated by HGWDE; however, the rest of the schemes are higher as compared to the proposed scheme. The starting peak of GWO is highest as compared to all other techniques.

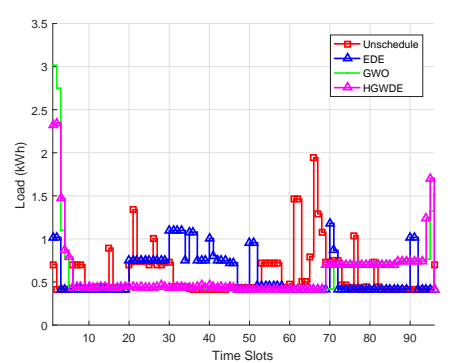

(a) Load 15-min OTI

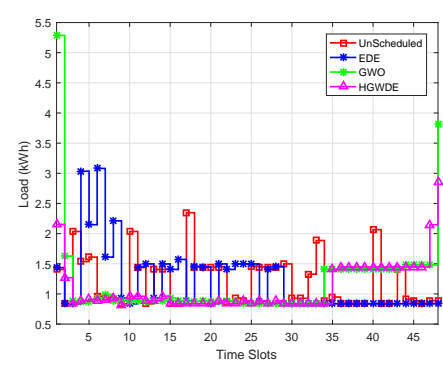

(b) Load 30-min OTI

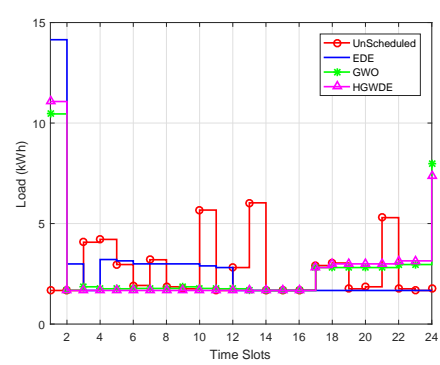

(c) Load 60-min OTI

Figure 7. Load per time slot for CPP.

Load stairs for 30-min OTI are shown in Figure 7b. For 60-min OTI, the load distribution for all schemes is shown in Figure 7c. The pattern of load distribution of HGWDE remains the same in all OTIs, but with variation in the total number of slots.

Total load must remain the same before and after scheduling. For 15-, 30- and 60-min OTI, total load for all schemes such as EDE, GWO and HGWDE is $56.3107 \mathrm{kWh}, 57.7655 \mathrm{kWh}$ and $64.5660 \mathrm{kWh}$, respectively. Hence, it is concluded that energy consumption remains the same; however, load is shifted to off-peak hours to achieve the objective function of cost minimization. 


\subsection{PAR}

PAR is given as the value of peak load formed during a time period of $24 \mathrm{~h}$ and an average of the total load consumed by a user. Our objective is to reduce PAR to ensure that minimal peaks are generated during $24 \mathrm{~h}$. Different strategies can be applied to reduce peaks such as peak clipping and valley filling, so that there will be no peaks in any time slot. In such a way, electricity cost will inevitably be reduced by compromising user comfort.

\subsubsection{PAR Using RTP}

PAR using RTP is represented in Figure 8a. In the unscheduled case, the value of PAR is 10.9697. PAR calculated for optimization techniques such as EDE and GWO is 8.1722 and 5.6750. However, our proposed hybrid scheme shows the best results with maximum PAR reduction as 5.1530. In terms of percentage, EDE, GWO and HGWDE show a PAR reduction of $25.50 \%, 48.26 \%$ and $53.02 \%$, respectively.

For 30-min OTI, the unscheduled PAR is recorded as 6.0257; however, it has been reduced to 5.8424 and 5.9335 when EDE and GWO are applied. The hybrid scheme outperforms both optimization schemes by reducing PAR to 3.6209. For 60-min OTI, EDE, GWO and HGWDE reduce PAR by a value of 3.6558, 4.3509 and 2.5369 as compared to the unscheduled scenario, which is 5.0244. Hence, it is clearly observed that HGWDE outperforms EDE and GWO in every scenario, as it performs efficiently in the variable OTIs.

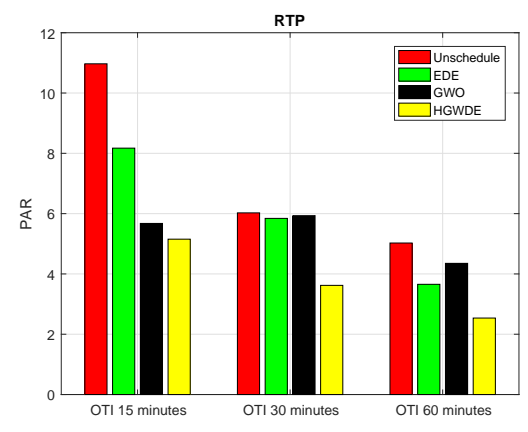

(a) PAR using RTP

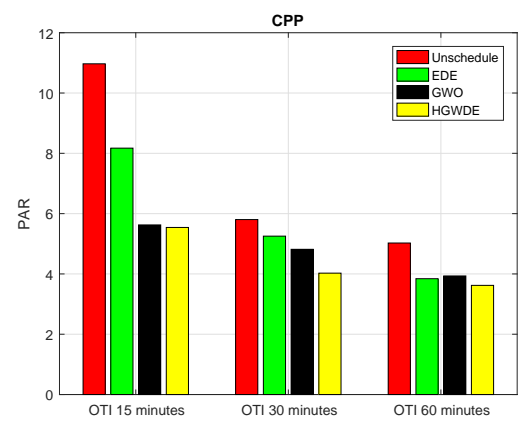

(b) PAR using CPP

Figure 8. PAR for different OTI's using RTP and CPP.

\subsubsection{PAR Using CPP}

Using CPP, scheduling is performed with EDE, GWO and HGWDE under multiple OTIs. Simulations of PAR under each OTI are shown in Figure 8b. For 15-min OTI, PAR for the unscheduled case is 10.9697. However, after performing scheduling on household appliances, PAR is reduced to 5.5415 with HGWDE, 5.626 with GWO and 8.1722 with EDE. In terms of percentage, a $49.4835 \%$, $48.71 \%$ and $25.50 \%$ reduction is achieved.

For 30-min OTI, the unscheduled PAR is recorded as 5.86. After scheduling with EDE, GWO and HGWDE, PAR is recorded as 5.2536, 4.8165 and 4.02, respectively. It can be observed from Table 8 that HGWDE outperforms all other techniques with multiple OTIs under different pricing schemes.

Table 8. PAR comparison of different techniques for $24 \mathrm{~h}$.

\begin{tabular}{ccccccc}
\hline \multirow{2}{*}{ Techniques } & \multicolumn{2}{c}{ PAR Using RTP with Multiple OTIs } & \multicolumn{3}{c}{ PAR Using CPP with Multiple OTIs } \\
\cline { 2 - 7 } & $\mathbf{1 5} \mathbf{~} \mathbf{m i n}$ & $\mathbf{3 0} \mathbf{~} \mathbf{m}$ & $\mathbf{6 0} \mathbf{~} \mathbf{i n}$ & $\mathbf{1 5} \mathbf{~} \mathbf{i n}$ & $\mathbf{3 0} \mathbf{~} i \mathbf{~}$ & $\mathbf{6 0} \mathbf{~ m i n}$ \\
\hline Unscheduled & 10.9697 & 6.0257 & 5.0257 & 10.9697 & 5.8034 & 5.0257 \\
EDE & 8.1722 & 5.8424 & 3.6558 & 8.1722 & 5.2536 & 3.8424 \\
GWO & 5.675 & 5.9335 & 4.3509 & 5.626 & 4.8165 & 3.9335 \\
HGWDE & 5.1530 & 3.6209 & 2.5369 & 5.5415 & 4.0263 & 3.6209 \\
\hline
\end{tabular}




\subsection{Waiting Time}

User comfort is related to waiting time. There is always a trade-off among different performance parameters. In this work, there is a trade-off between cost and user comfort. To minimize the cost, the user has to wait for off-peak hours to switch on a particular appliance. Hence, there is a direct relationship between user comfort and cost [42]. In the unscheduled case, waiting time is zero, as appliances are being switched on according to the user's demand. However, in the scheduled case, the user has to compromise on comfort if cost minimization is the main objective.

\subsubsection{Waiting Time Using RTP}

Figure 9a represents the waiting time for 15-, 30- and 60-min OTI. Waiting time for EDE, GWO and HGWDE is calculated as $4.3 \mathrm{~h}, 9.7 \mathrm{~h}$ and $10.4 \mathrm{~h}$, respectively. Waiting time for 30-min OTI is calculated as $4.5394 \mathrm{~h}, 10.0262 \mathrm{~h}$ and $12.7007 \mathrm{~h}$. Similarly, for 60-min OTI, waiting time is $2.6560 \mathrm{~h}, 2.2397 \mathrm{~h}$ and $3.8 \mathrm{~h}$, respectively.

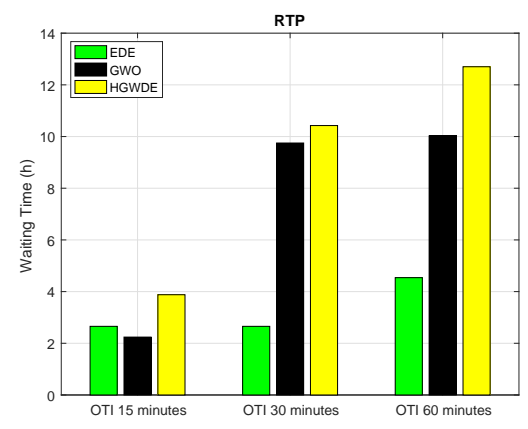

(a) Waiting time using RTP

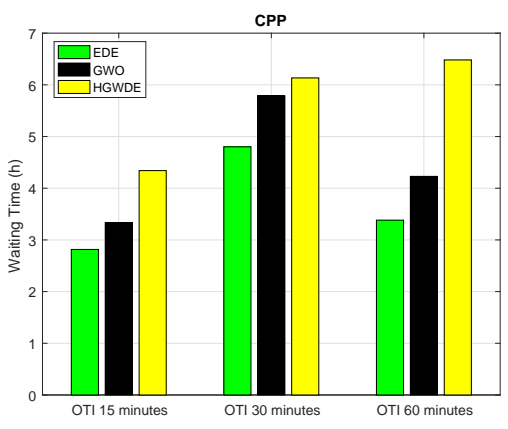

(b) Waiting time using $\mathrm{CPP}$

Figure 9. Average waiting time of appliances using RTP and CPP.

From the results, it is concluded that keeping the OTI smaller always reduces the waiting time. For example, if a toaster has an operational time of $12 \mathrm{~min}$, then a toaster will consume one time slot of $15 \mathrm{~min}$; in this way, only $2 \mathrm{~min}$ are being wasted because in this slot, no other appliance can be turned on. In contrast, if an OTI is $60 \mathrm{~min}$ and a kettle has an operational time of $5 \mathrm{~min}$, then $55 \mathrm{~min}$ will be wasted. The slot of $60 \mathrm{~min}$ is reserved for the kettle; hence, no other appliance can be turned on, so the waiting time will increase.

\subsubsection{Waiting time using CPP}

Simulations represent that the waiting time is a trade-off parameter, while minimizing the cost. Waiting time of all implemented optimization schemes using CPP is shown in Figure 9b. Waiting time for EDE, GWO and HGWDE is recorded as $3.38 \mathrm{~h}, 4.22 \mathrm{~h}$ and $6.48 \mathrm{~h}$, respectively. It can be clearly observed that HGWDE has the highest waiting time, which means that user comfort is being compromised for the sake of minimizing the electricity bill. Waiting time for EDE, GWO and HGWDE is given in Table 9.

Table 9. Waiting time comparison of different techniques for $24 \mathrm{~h}$.

\begin{tabular}{|c|c|c|c|c|c|c|}
\hline \multirow{2}{*}{ Techniques } & \multicolumn{3}{|c|}{ Waiting Time Using RTP with Multiple OTIs } & \multicolumn{3}{|c|}{ Waiting Time Using CPP with Multiple OTIs } \\
\hline & $15 \mathrm{~min}$ & $30 \mathrm{~min}$ & $60 \mathrm{~min}$ & $15 \mathrm{~min}$ & $30 \mathrm{~min}$ & $60 \mathrm{~min}$ \\
\hline EDE & $4.3781 \mathrm{~h}$ & $4.5394 \mathrm{~h}$ & $2.6560 \mathrm{~h}$ & $3.3826 \mathrm{~h}$ & $4.8012 \mathrm{~h}$ & $2.8158 \mathrm{~h}$ \\
\hline GWO & $9.7494 \mathrm{~h}$ & $10.0262 \mathrm{~h}$ & $2.2397 \mathrm{~h}$ & $4.2293 \mathrm{~h}$ & $5.7853 \mathrm{~h}$ & $3.3346 \mathrm{~h}$ \\
\hline HGWDE & $10.4249 \mathrm{~h}$ & $12.7007 \mathrm{~h}$ & $3.8793 \mathrm{~h}$ & $6.4814 \mathrm{~h}$ & $6.1335 \mathrm{~h}$ & $4.3408 \mathrm{~h}$ \\
\hline
\end{tabular}




\subsection{Convergence of the Fitness Function}

Figure 10 represents the convergence of the fitness function for our proposed scheme. On the $y$ axis, the value of the fitness function is plotted, while the $x$ axis shows the number of iterations. The figure shows that the solution starts to converge after the 30th iteration, which means that the optimizer has achieved the global maximum. The convergence behavior of HGWDE is plotted for each iteration. From $0-5$ iterations, the value of the cost is constantly decreasing, and after that, a slight variation can be observed in the graph. The number of iterations is taken as 50. Finally, a straight line is obtained, which is the most optimal point where a solution can converge.

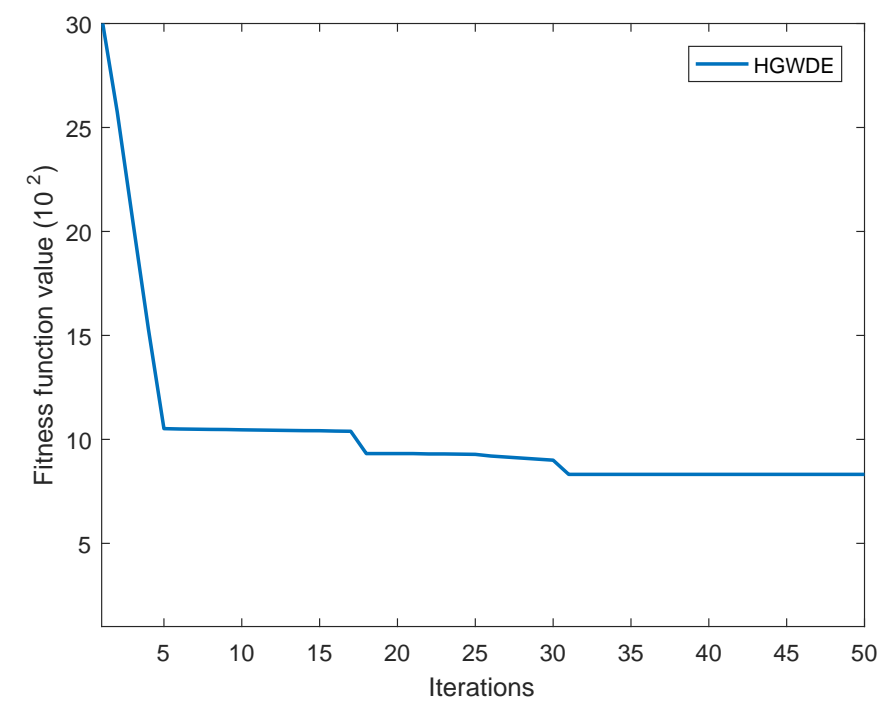

Figure 10. Evolution of the cost function.

\subsection{Feasible Region}

The feasible region is a bounded area plotted by a specific set of points. A shaded region under a plotted region shows our objective function, which is the feasible solution to our problem. Minimum and maximum costs are plotted under specific constraints of the system.

\subsubsection{Feasible Region Using RTP}

\section{a. Feasible Region under 15-min OTI}

The feasible region is plotted to figure out how much cost is reduced by controlling the consumption of electricity. The RTP scheme is used as a pricing signal. The main objective is to calculate the total maximum and minimum cost against the maximum and minimum load. Four points are calculated using min-max combinations of pricing signal and total load. The RTP signal ranges from 8.100 cents $/ \mathrm{kWh}-27.35$ cents $/ \mathrm{kWh}$. Total energy consumption under 96 time slots ranges from $0.4177 \mathrm{kWh}-3.54 \mathrm{kWh}$. Possible cases for these minimum and maximum points are calculated as shown in Table 10.

Total covered area is obtained under Points P1(3.38, 28.75), P2(8.17, 70), P4(11.42, 28.75), P5(11.42, 96.95). The region under these points shows the area for the possible solution, but not the feasible solution. To calculate the feasible region, Point P3 $(11.42,70)$ is added to get the desired area. This means that electricity cost should be less than 70 cents to achieve the objective function of the minimal cost. The overall feasible region is obtained against coordinates P1, P2, P3, P4 and P5. The feasible region for 15-min OTI using RTP is shown in Figure 11a. 


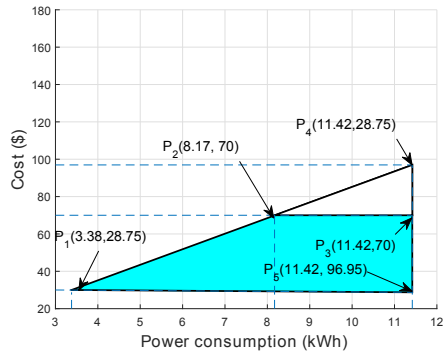

(a) Feasible region for 15-min OTI

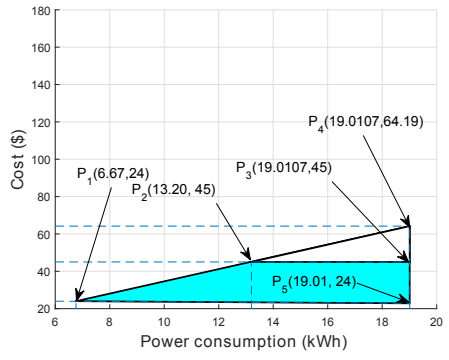

(b) Feasible region for 30-min OTI

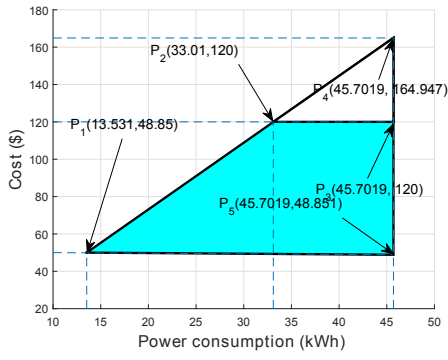

(c) Feasible region for 60-min OTI

Figure 11. Feasible region for multiple OTIs using RTP.

Table 10. Possible cases: OTI 15-min using RTP.

\begin{tabular}{cccc}
\hline Cases & Price (Cents) & Load (kWh) & Cost (Cents) \\
\hline Min Price, Min Load & 8.100 & 0.4177 & 3.38 \\
Min Price, Max Load & 8.100 & 3.54 & 28.75 \\
Max Price, Min Load & 27.35 & 0.4177 & 11.42 \\
Max Price, Max Load & 27.35 & 3.54 & 96.95 \\
\hline
\end{tabular}

\section{b. Feasible Region under 30-min OTI}

For 48 time slots, the total cost for the unscheduled case is considered. Possible points are calculated using the min-max combinations of price and energy consumption. The main objective is to calculate the total maximum and minimum cost against maximum and minimum load. Reducing the overall energy consumption would ultimately result in cost reduction to achieve the economic goals for a consumer. Electricity price defined by the utility ranges from 8.100 cents $/ \mathrm{kWh}-27.35$ cents $/ \mathrm{kWh}$, and the minimum and maximum load ranges from $0.83 \mathrm{kWh}-2.34 \mathrm{kWh}$. Table 11 shows the values of different points. Total covered area is obtained under Points P1(6.67, 24), P2(13.20, 45), P4 (19.01, 64.19), P5 $(19.01,24)$. To represent the feasible region, Point P3 $(19.01,45)$ is plotted, meaning that the electricity cost should be less than 45 cents to achieve the objective function of the minimal cost, so all five points P1, P2, P3, P4 and P5 collectively form our feasible region for cost reduction by minimizing energy consumption. The feasible region for 30-min OTI using RTP is shown in Figure 11b.

Table 11. Possible cases: OTI 30-min using RTP.

\begin{tabular}{cccc}
\hline Cases & Price (Cents) & Load (kWh) & Cost (Cents) \\
\hline Min Price, Min Load & 8.100 & 0.8355 & 6.76 \\
Min Price, Max Load & 8.100 & 2.34 & 19.0107 \\
Max Price, Min Load & 27.35 & 0.8355 & 22.8509 \\
Max Price, Max Load & 27.35 & 2.34 & 69.1904 \\
\hline
\end{tabular}

\section{c. Feasible Region under 60-min OTI}

The feasible region for 60-min OTI is calculated in the same way as above. However, the overall obtained area and the feasible area for our objective function are different. The overall area is obtained under four coordinates as P1(13.53, 48.85), P2(33.01, 120), P4(45.70, 164.94) and P5(45.70, 48.851). The overall area shows the unscheduled cost; however, after scheduling, the cost has been reduced comparatively. To show the cost reduction after scheduling, the feasible region is plotted, which is a sub area of the overall region. The electricity price defined by the utility ranges from 8.100 cents $/ \mathrm{kWh}-27.35$ cents $/ \mathrm{kWh}$, and minimum and maximum loads range from $0.83 \mathrm{kWh}-2.34 \mathrm{kWh}$. Table 12 shows the values of different points. To represent the feasible region, 
Point P3 $(45.70,120)$ is added, which describes the actual area. The feasible region for 60-min OTI using RTP is shown in Figure 11c.

Table 12. Possible cases: OTI 60-min using RTP.

\begin{tabular}{cccc}
\hline Cases & Price (Cents) & Load (kWh) & Cost (Cents) \\
\hline Min Price, Min Load & 8.100 & 1.67 & 13.531 \\
Min Price, Max Load & 8.100 & 6.03 & 45.7019 \\
Max Price, Min Load & 27.35 & 1.67 & 48.851 \\
Max Price, Max Load & 27.35 & 6.03 & 164.947 \\
\hline
\end{tabular}

\subsubsection{Feasible Region Using CPP}

\section{a. Feasible Region under 15-min OTI}

The feasible region is calculated by changing the pricing scheme to CPP. To calculate the feasible region, the minimum and maximum unscheduled load and price of electricity are calculated. Four possible cases are taken into consideration as given in Table 13: P1(4.7615, 51.544), P2(13.8, 150), $\mathrm{P} 4(22.1479,239.7415), \mathrm{P} 5(22.1479,51.544)$. These four points are used to get the overall region for the possible search space. However, a feasible region is obtained for our objective function at Point P3 $(22.1479,150)$. For the feasible region, Point P3 cuts the overall area at 150 cents on the y axis, which shows the maximum cost in the scheduled case. The feasible region for 15-min OTI using CPP is shown in Figure 12a.

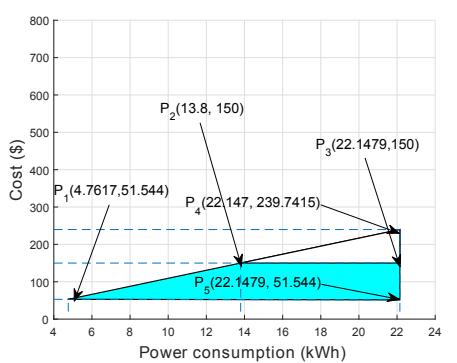

(a) Feasible region for 15-min OTI

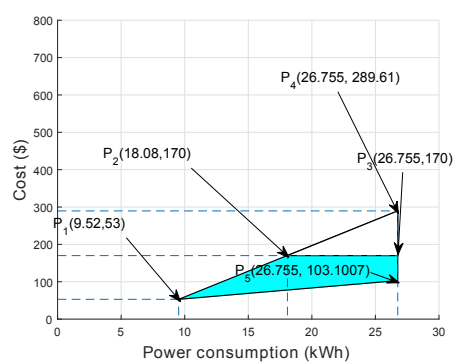

(b) Feasible region for 30-min OTI

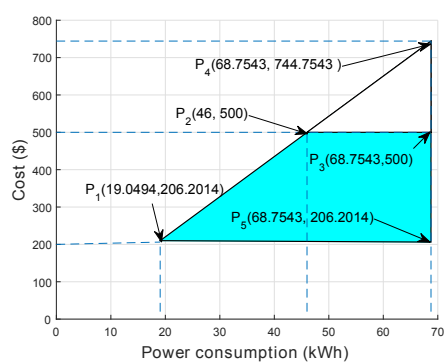

(c) Feasible region for 60-min OTI

Figure 12. Feasible region for multiple OTIs using CPP.

Table 13. Possible cases: OTI 15-min using CPP.

\begin{tabular}{cccc}
\hline Cases & Price (Cents) & Load (kWh) & Cost (Cents) \\
\hline Min Price, Min Load & 11.4 & 0.4177 & 4.76178 \\
Min Price, Max Load & 11.4 & 1.9428 & 22.14792 \\
Max Price, Min Load & 123.4 & 0.4177 & 51.544 \\
Max Price, Max Load & 123.4 & 1.9428 & 239.74152 \\
\hline
\end{tabular}

\section{b. Feasible Region under 30-min OTI}

Different feasible regions are calculated to evaluate the effect of cost by changing the OTI. In this case, OTI is taken as $30 \mathrm{~min}$, which means that each hour is divided into two time slots. Minimum and maximum unscheduled loads are calculated under the CPP scheme. Combinations of min-max load and electricity price are shown in Table 14. As a result, four possible combinations are obtained: P1 $(9.52,53), \mathrm{P} 2(18.08,170), \mathrm{P} 4(26.755,289.61)$, and P5(26.755, 103.1007). The overall region is cut out at Point $\mathrm{P} 3(26.755,170)$, which shows the actual area of our objective function. This means that after scheduling, the cost should be less than 170 cents. The feasible region for 30-min OTI using CPP is shown in Figure 12b. 
Table 14. Possible Cases: OTI 30-min using CPP.

\begin{tabular}{cccc}
\hline Cases & Price (Cents) & Load (kWh) & Cost (Cents) \\
\hline Min Price, Min Load & 11.4 & 0.8355 & 9.5247 \\
Min Price, Max Load & 11.4 & 2.3470 & 26.7558 \\
Max Price, Min Load & 123.4 & 0.8355 & 103.1007 \\
Max Price, Max Load & 123.4 & 2.3470 & 289.6198 \\
\hline
\end{tabular}

\section{c. Feasible Region under 60-min OTI}

For 60-min OTI, the feasible region is calculated for 24 time slots. Similarly, four possible set points are calculated. Table 15 represents the four coordinates on the $x$ and $y$ axes as P1(19.0494, 2016.2014), $\mathrm{P} 2(46,500), \mathrm{P} 4(68.7543,744.7543)$ and $\mathrm{P} 5(68.7543,206.2014) . \mathrm{P} 3(68.7543,500)$ is obtained to show the actual feasible region where the scheduled cost should be less than 500 cents.

Results show that the maximum scheduled cost observed under 60-min OTI is 500 cents, as shown in Figure 12c.

Table 15. Possible cases: OTI 60-min using CPP.

\begin{tabular}{cccc}
\hline Cases & Price (Cents) & Load (kWh) & Cost (Cents) \\
\hline Min Price, Min Load & 11.4 & 1.6710 & 19.0494 \\
Min Price, Max Load & 11.4 & 6.0310 & 68.7534 \\
Max Price, Min Load & 123.4 & 1.6710 & 206.2014 \\
Max Price, Max Load & 123.4 & 6.0310 & 744.2254 \\
\hline
\end{tabular}

\subsection{Performance Trade-Off}

There is always some trade-off in different performance parameters. In HEM, the main objective is to reduce cost, while user comfort is compromised. User discomfort increases whenever there is a high difference in the user's preferred time and the scheduled time to switch on an appliance. From Figure $4 \mathrm{a}, \mathrm{b}$, it is concluded that the minimum cost is achieved by applying HGWDE, but with maximum average waiting time.

\section{Conclusions and Future Work}

To maintain the stability of the grid, the traditional grid is revolutionized into a smart grid. DSM and DR are the key factors to maintain the balance between electricity demand and supply. DSM helps with minimizing the electricity cost for end users and the stable operation of the grid. In this paper, the cost and PAR reduction scheme is proposed for the residential sector by considering multiple OTIs. HGWDE is proposed under two different pricing schemes: RTP and CPP. The performance of the proposed scheme is evaluated by implementing it on a single home with multiple appliances under different pricing schemes. Feasible regions are calculated for each OTI, which describe the effect of scheduling the appliances in terms of electricity cost and waiting time.

Four performance parameters are taken into consideration to evaluate the performance of the proposed scheme. It is observed that the implemented scheme helps to schedule the electricity load from high price hours to low price hour. Hence, the cost minimization and PAR minimization are achieved with reasonable waiting time. From the results, it is concluded that HGWDE outperforms the existing techniques. However, there is a trade-off between electricity cost and waiting time.

In the future, multiple heuristic optimization techniques will be explored for cost and PAR reduction with the integration of RES. Another future research direction is to implement the cloud concept for the scheduling of home appliances rather than using an EMC.

Acknowledgments: This project was full financially supported by the King Saud University, through the Vice Deanship of Research Chairs. 
Author Contributions: Muqaddas Naz, Zafar Iqbal, Nadeem Javaid, and Zahoor Ali Khan proposed, implemented and wrote the heuristic schemes. Wadood Abdul, Ahmad Almogren and Atif Alamri wrote rest of the paper. All authors together organized and refined the paper.

Conflicts of Interest: The authors declare no conflict of interest.

\section{References}

1. Mhanna, S.; Chapman, A.C.; Verbi, G. A fast distributed algorithm for large-scale demand response aggregation. IEEE Trans. Smart Grid 2016, 7, 2094-2107.

2. Energy Reports. Available online: http://www.enerdata.net/enerdatauk/press-and-publication/energyfeatures/enerfuture-2007.php (accessed on 1 August 2015).

3. Logenthiran, T.; Srinivasan, D.; Shun, T.Z. Demand side management in smart grid using heuristic optimization. IEEE Trans. Smart Grid 2012, 3, 1244-1252.

4. Shirazi, E.; Jadid, S. Optimal residential appliance scheduling under dynamic pricing scheme via HEMDAS. Energy Build. 2015, 93, 40-49.

5. Bradac, Z.; Kaczmarczyk, V.; Fiedler, P. Optimal scheduling of domestic appliances via MILP. Energies 2014, $8,217-232$.

6. Teets, W. The association between stock market responses to earnings announcements and regulation of electric utilities. J. Account. Res. 1992, 30, 274-285.

7. Mahmood, A.; Javaid, N.; Khan, N.A.; Razzaq, S. An optimized approach for home appliances scheduling in smart grid. In Proceedings of the 2016 19th International Multi-Topic Conference (INMIC), Islamabad, Pakistan, 5-6 December 2016; pp. 1-5.

8. Veras, J.M.; Pinheiro, P.R.; Silva, I.R.S.; Rabêlo, R.A. A Demand Response Optimization Model for Home Appliances Load Scheduling. In Proceedings of the 2017 IEEE International Conference on Systems, Man, and Cybernetics (SMC), Banff, AB, Canada, 5-8 October 2017.

9. Ahmad, A.; Khan, A.; Javaid, N.; Hussain, H.M.; Abdul, W.; Almogren, A.; Alamri, A.; Azim Niaz, I. An Optimized Home Energy Management System with Integrated Renewable Energy and Storage Resources. Energies 2017, 10, 549.

10. Javaid, N.; Naseem, M.; Rasheed, M.B.; Mahmood, D.; Khan, S.A.; Alrajeh, N.; Iqbal, Z. A new heuristically optimized Home Energy Management controller for smart grid. Sustain. Cities Soc. 2017, 34, 211-227.

11. Rahimi, F.; Ipakchi, A. Demand response as a market resource under the smart grid paradigm. IEEE Trans. Smart Grid 2010, 1, 82-88.

12. Yang, H.T.; Yang, C.T.; Tsai, C.C.; Chen, G.J.; Chen, S.Y. Improved PSO based home energy management systems integrated with demand response in a smart grid. In Proceedings of the 2015 IEEE Congress on Evolutionary Computation (CEC), Sendai, Japan, 25-28 May 2015; pp. 275-282.

13. Ogwumike, C.; Short, M.; Abugchem, F. Heuristic Optimization of Consumer Electricity Costs using a Generic Cost Model. Energies 2016, 9, 6.

14. Rasheed, M.B.; Javaid, N.; Ahmad, A.; Khan, Z.A.; Qasim, U.; Alrajeh, N. An efficient power scheduling scheme for residential load management in smart homes. Appl. Sci. 2015, 5, 1134-1163.

15. Tuaimah, F.M.; Abd, Y.N.; Hameed, F.A. Ant Colony Optimization based Optimal Power Flow Analysis for the Iraqi Super High Voltage Grid. Int. J. Comput. Appl. 2013, 67, 13-18.

16. Logenthiran, T.; Srinivasan, D.; Vanessa, K.W.M. Demand side management of smart grid: Load shifting and incentives. J. Renew. Sustain. Energy 2014, 6, 033136.

17. Islam, S.M.; Das, S.; Ghosh, S.; Roy, S.; Suganthan, P.N. An adaptive differential evolution algorithm with novel mutation and crossover strategies for global numerical optimization. IEEE Trans. Syst. Man Cybern. Part B (Cybern.) 2012, 42, 482-500.

18. Li, H.; Zhang, Q. Multiobjective optimization problems with complicated Pareto sets, MOEA/D and NSGA-II. IEEE Trans. Evol. Comput. 2009, 13, 284-302.

19. Setlhaolo, D.; Xia, X. Optimal scheduling of household appliances incorporating appliance coordination. Energy Proc. 2014, 61, 198-202.

20. Osório, G.J.; Matias, J.C.O.; Catalão, J.P.S. Electricity prices forecasting by a hybrid evolutionary-adaptive methodology. Energy Convers. Manag. 2014, 80, 363-373. 
21. Shayeghi, H.; Ghasemi, A.; Moradzadeh, M.; Nooshyar, M. Simultaneous day-ahead forecasting of electricity price and load in smart grids. Energy Convers. Manag. 2015, 95, 371-384.

22. Derakhshan, G.; Shayanfar, H.A.; Kazemi, A. The optimization of demand response programs in smart grids. Energy Policy 2016, 94, 295-306.

23. Soares, J.; Ghazvini, M.A.F.; Vale, Z.; de Moura Oliveira, P.B. A multi-objective model for the day-ahead energy resource scheduling of a smart grid with high penetration of sensitive loads. Appl. Energy 2016, 162, 1074-1088.

24. Ghasemi, A.; Shayeghi, H.; Moradzadeh, M.; Nooshyar, M. A Novel hybrid algorithm for electricity price and load forecasting in smart grids with demand-side management. Appl. Energy 2016, 177, 40-59.

25. Jayabarathi, T.; Raghunathan, T.; Adarsh, B.R.; Suganthan, P.N. Economic dispatch using hybrid grey wolf optimizer. Energy 2016, 111, 630-641.

26. Lugo-Cordero, H.M.; Fuentes-Rivera, A.; Guha, R.K.; Ortiz-Rivera, E.I. Particle swarm optimization for load balancing in green smart homes. In Proceedings of the 2011 IEEE Congress of Evolutionary Computation(CEC), New Orleans, LA, USA, 5-8 June 2011; pp. 715-720.

27. Geem, Z.W.; Kim, J.H.; Loganathan, G.V. A new heuristic optimization algorithm: Harmony 578 search. Simulation 2001, 76, 60-68.

28. Storn, R.; Price, K. Differential Evolution-A Simple and Efficient Adaptive Scheme for Global 580 Optimization over Continuous Spaces; International Computer Science Institute: Berkeley, CA, USA, 1995.

29. Vardakas, J.S.; Zorba, N.; Verikoukis, C.V. Performance evaluation of power demand scheduling scenarios in a smart grid environment. Appl. Energy 2015, 142, 164-178.

30. Yi, P.; Dong, X.; Iwayemi, A.; Zhou, C.; Li, S. Real-time opportunistic scheduling for residential demand response. IEEE Trans. Smart Grid 2013, 4, 227-234.

31. Yuce, B.; Rezgui, Y.; Mourshed, M. ANN-GA smart appliance scheduling for optimised energy management in the domestic sector. Energy Build. 2016, 111, 311-325.

32. Reka, S.S.; Ramesh, V. A demand response modeling for residential consumers in smart grid environment using game theory based energy scheduling algorithm. Ain Shams Eng. J. 2016, 7, 835-845.

33. Erdinc, O. Economic impacts of small-scale own generating and storage units, and electric vehicles under different demand response strategies for smart households. Appl. Energy 2014, 126, 142-150.

34. Agnetis, A.; de Pascale, G.; Detti, P.; Vicino, A. Load scheduling for household energy consumption optimization. IEEE Trans. Smart Grid 2013, 4, 2364-2373.

35. Setlhaolo, D.; Xia, X.; Zhang, J. Optimal scheduling of household appliances for demand response. Electr. Power Syst. Res. 2014, 116, 24-28.

36. Pradhan, M.; Roy, P.K.; Pal, T. Grey wolf optimization applied to economic load dispatch problems. Int. J. Electr. Power Energy Syst. 2016, 83, 325-334.

37. Javaid, N.; Ullah, I.; Akbar, M.; Iqbal, Z.; Khan, F.A.; Alrajeh, N.; Alabed, M.S. An intelligent load management system with renewable energy integration for smart homes. IEEE Access 2017, 5, 13587-13600.

38. Vardakas, J.S.; Zorba, N.; Verikoukis, C.V. Power demand control scenarios for smart grid applications with finite number of appliances. Appl. Energy 2016, 162, 83-98.

39. Ogunjuyigbe, A.S.O.; Ayodele, T.R.; Akinola, O.A. User satisfaction-induced demand side load management in residential buildings with user budget constraint. Appl. Energy 2017, 187, 352-366.

40. Singh, N.; Singh, S.B. Hybrid Algorithm of Particle Swarm Optimization and Grey Wolf Optimizer for Improving Convergence Performance. J. Appl. Math. 2017, 2017, 2030489.

41. Waterloo North Hydro. Available online: https://www.wnhydro.com/en/your-home/time-of-use-rates. asp (accessed on 6 December 2017).

42. Muralitharan, K.; Sakthivel, R.; Shi, Y. Multiobjective optimization technique for demand side management with load balancing approach in smart grid. Neurocomputing 2016, 177, 110-119.

(C) 2018 by the authors. Licensee MDPI, Basel, Switzerland. This article is an open access article distributed under the terms and conditions of the Creative Commons Attribution (CC BY) license (http:// creativecommons.org/licenses/by/4.0/). 